Supporting Information for

\title{
Direct sequencing of tRNA by 2D-HELS-AA MS Seq reveals its different isoforms and dynamic base modifications
}

Ning Zhang ${ }^{1 \mathrm{a}, 2}$, Shundi Shi ${ }^{2}$, Xuanting Wang ${ }^{2}$, Wenhao Ni ${ }^{1 \mathrm{a}}$, Xiaohong Yuan ${ }^{1 \mathrm{a}}$, Jiachen Duan $^{1 \mathrm{a}}$, Tony Z. Jia ${ }^{3,4}$, Barney Yoo ${ }^{5}$, Ashley Ziegler ${ }^{1 \mathrm{a}}$, James J. Russo ${ }^{2}$, Wenjia Li ${ }^{1 \mathrm{~b}}$, Shenglong Zhang ${ }^{1 \mathrm{a} *}$

${ }^{1 a}$ Department of Biological and Chemical Sciences, New York Institute of Technology, New York, NY 10023, USA.

${ }^{1 b}$ Department of Computer Science, New York Institute of Technology, New York, NY 10023, USA.

${ }^{2}$ Department of Chemical Engineering, Columbia University, New York, NY 10027, USA.

${ }^{3}$ Earth-Life Science Institute, Tokyo Institute of Technology, Meguro-ku, Tokyo, 152-8550, Japan.

${ }^{4}$ Blue Marble Space Institute of Science, Seattle, WA 98154, USA.

${ }^{5}$ Department of Chemistry, Hunter College, City University of New York, New York, NY 10065, USA.

* To whom correspondence should be addressed. Tel: +1-212-261-1634; Fax: +1-212-261-1634; Email:

szhang21@nyit.edu

KEYWORDS: Direct RNA sequencing, 2D-HELS-AA MS Seq, RNA modification sequencing and quantification, RNA isoform detection

This PDF file includes:

Materials and Methods

Figures S1 to S7

Tables S1 to S25

SI References 


\section{Materials and Methods}

\section{Reagents and Chemicals}

All chemicals were purchased from commercial sources and used without further purification. tRNA (phenylalanine specific from brewer's yeast), ATP $\gamma \mathrm{S}$ (adenosine-5'-( $\gamma$-thio)-triphosphate), and T4 polynucleotide kinase ( 3 '-phosphatase free) were obtained from Sigma-Aldrich (St. Louis, Missouri, USA). RNase T1, 10× RNA structure buffer, polynucleotide kinase (3'-phosphatase free) and SuperScript IV reverse transcriptase were obtained from Thermo Fisher Scientific (Waltham, MA, USA). Formic acid (98-100\%) was purchased from Merck KGaA (Darmstadt, Germany). Adenosine-5'-5'-diphosphate- $\left\{5^{\prime}\right.$-(cytidine-2'-O-methyl-3'-phosphate-TEG $\}$-biotin $(\mathrm{AppCpB)} \mathrm{was} \mathrm{synthesized} \mathrm{by} \mathrm{ChemGenes} \mathrm{(Wilmington,} \mathrm{MA,} \mathrm{USA).} \mathrm{T4} \mathrm{DNA} \mathrm{ligase} \mathrm{(400}$ units/ $\mu \mathrm{L}$ ) and T4 DNA ligase buffer (10x) were purchased from New England Biolabs (Ipswich, MA, USA). Biotin (long arm) maleimide was purchased from Vector Laboratories (Burlingame, CA, USA). AlkB homolog 3, alpha-ketoglutaratedependent dioxygenase (ALKBH3, $2 \mu \mathrm{g} / \mu \mathrm{L}$ ) was purchased from Active Motif (Carlsbad, CA, USA). All other chemicals, including $N$ cyclohexyl- $N^{\prime}$-(2-morpholinoethyl)-carbodiimide metho- $p$-toluenesulfonate (CMC), bicine, urea, ethylenediaminetetraacetic acid (EDTA), sodium carbonate $\left(\mathrm{Na}_{2} \mathrm{CO}_{3}\right)$, sodium acetate $(\mathrm{NaOAc})$, borohydride $\left(\mathrm{NaBH}_{4}\right)$, aniline, Tris (2-amino-2-(hydroxymethyl)propane-1,3-diol)-HCl buffer (1 $\mathrm{M}, \mathrm{pH} 7.5)$, magnesium chloride $\left(\mathrm{MgCl}_{2}\right)$, and potassium chloride $(\mathrm{KCl})$, were obtained from Sigma-Aldrich unless indicated otherwise.

\section{tRNA sample preparation for LC-MS}

To ensure that each degraded fragment in the tRNA can be detected on a standard high-resolution liquid chromatography quadrupole time-of-flight mass spectrometry (LC-Q-TOF-MS), an amount of approximately 350 pmol tRNA sample is required for each liquid chromatography-mass spectrometry (LC-MS) run. For preparation of this amount of tRNA sample for the LC-MS analysis, we performed the following experiments.

Partial RNase T1 digestion and 3'-biotinylation tRNA (generation of Figures $1 B$ and S1A): Approximately $4 \mu \mathrm{g}$ (150 pmol) of tRNA (phenylalanine specific from brewer's yeast) was digested by $1 \mu \mathrm{L}$ of $1 \mathrm{U} / \mu \mathrm{L}$ RNase T1 in $1 \times$ RNA structure buffer at room temperature for $65 \mathrm{hrs}$. To maintain the best enzymatic efficacy for $\mathrm{T} 1$ digestion, five parallel reactions in total were performed in a small reaction volume $(10 \mu \mathrm{L})$ separately. The digestion products were purified by 
Oligo Clean \& Concentrator (Zymo Research, Irvine, CA, USA). We monitored the partial digestion by LC-MS and about 40\% tRNA was digested into three segments, which we named segments I, II, and III; the remaining fraction consisted of incompletely digested tRNA fragments and full length tRNA that was not digested at all. After purification by Oligo Clean \& Concentrator, the 3 '-end of the purified partially digested tRNA was labeled by biotin using a previously published method. ${ }^{1}$ After 3 '-biotin-labeling and column purification, we performed streptavidincoupled beads' catch and release to harvest the 3'-biotinylated RNase T1 partially digested tRNA, which contains 3'-biotin-labeled segment III and 3'-biotin-labeled full length tRNA as well as a part of unlabeled segments I and II. The reasons for the presence of unlabeled segments I and II are due to 1) the incomplete cut caused the co-existence of segments II and III and 2) the stemloop intramolecular base pairing between positions 1-7 and 66-72 caused the co-existence of segments I and III. This sample was sequenced by a previously published method after acid degradation followed by LC-MS analysis. ${ }^{l}$ Please note that not only can we read out the sequence of segment III (Figure S1A), we can also read out all sequences of segments I, II, and III by our anchor-based algorithm using their specific anchors (Figure 1B).

In order to confirm the sequences we read out from the above-described sample, the residue from streptavidin-coupled beads' catch and release, which contains segment I, segment II, and undigested unlabeled tRNA, was saved for further labeling of segments I and II in the following steps.

Labeling segment II (Generation of Figure S1B): The residue after streptavidin-coupled beads' catch and release from the previous step was concentrated, desalted by oligo concentrator, and used for the $5^{\prime}-\mathrm{OH}$ biotin-labeling of segment II. $5^{\prime}$-end-labeling was performed in two steps as previously reported. ${ }^{l}$ A biotin streptavidin capture method was used to purify the $5^{\prime}$-OH biotin labeled segment II. The residue, which contains segment I and undigested total tRNA, was saved for further labeling of segment I in the next step. Labeled segment II was acid degraded, followed by LC-MS sequencing. ${ }^{I}$ The sequence of segment II was read out by our anchor-based algorithm using the biotin anchor (Figure S1B).

Labeling segment I (Generation of Figure S1C): The residue of purification products from the previous step was further processed for 5'-dephosphorylation and 5'-OH biotin labeling of segment I. This step can also be accomplished with full-length intact tRNA. 5'-dephosphorylation is needed to generate a $5^{\prime}-\mathrm{OH}$ before labeling the $5^{\prime}$-end of segment I or full-length intact tRNA. 
Then, the same procedure was employed to label $5^{\prime}-\mathrm{OH}$ with the biotin of segment I and fulllength intact tRNA. Labeled segment I was acid degraded, followed by LC-MS sequencing. ${ }^{1}$ The sequence of segment I was read out by our anchor-based algorithm using the biotin anchor (Figure $\mathrm{S} 1 \mathrm{C})$. The protocol of $5^{\prime}$-dephosphorylation is as follows: $2 \mu \mathrm{L}$ of alkaline phosphatase $(20 \mathrm{U} / \mu \mathrm{L})$ was added to the above described tRNA sample containing segment I. The reaction was incubated at $50{ }^{\circ} \mathrm{C}$ for $60 \mathrm{~min}$ followed by purification by Oligo Clean \& Concentrator.

\section{Chemistry for differentiating pseudouridine $(\psi)$ from uridine}

The experiments to convert $\psi$ into $\mathrm{CMC}-\psi$ adducts were performed using a modified protocol according to reported methods. ${ }^{1,2} 10 \mu \mathrm{g}$ (400 pmol) of tRNA after RNase T1 partial digestion was denatured in $5 \mathrm{mM}$ EDTA at $80{ }^{\circ} \mathrm{C}$ for $2 \mathrm{~min}$ and then placed on ice. The sample was then treated with $0.17 \mathrm{M} \mathrm{CMC}$ in $50 \mathrm{mM}$ bicine, $\mathrm{pH} 8.3,4 \mathrm{mM}$ EDTA, and $7 \mathrm{M}$ urea at $37{ }^{\circ} \mathrm{C}$ for $17 \mathrm{hrs}$ in a total reaction volume of $90 \mu \mathrm{L}$. The reaction was stopped by addition of $60 \mu \mathrm{L}$ of a solution of 1.5 $\mathrm{M}$ sodium acetate $(\mathrm{NaOAc})$ and $0.5 \mathrm{mM}$ EDTA, pH 5.6 NaOAc buffer. After purification using Oligo Clean \& Concentrator, $60 \mu \mathrm{L}$ of $\mathrm{Na}_{2} \mathrm{CO}_{3}$ buffer (0.1 M, pH 10.4) was added to the solution, the solution was brought to a reaction volume of $120 \mu \mathrm{L}$ by addition of nuclease-free, deionized water, and the sample was then incubated at $55^{\circ} \mathrm{C}$ for $2 \mathrm{hrs}$. The reaction was stopped with $60 \mu \mathrm{L}$ of NaOAc buffer (1.5 M, pH 5.5) and purified by Oligo Clean \& Concentrator for LC-MS analysis.

\section{Chemistry for aniline-induced cleavage at $\mathbf{m}^{7} \mathrm{G}$ (7-methylguanosine)}

We treated tRNA with borohydride $\left(\mathrm{NaBH}_{4}\right)$ and aniline sequentially to generate a site-specific cleavage right after $\mathrm{m}^{7} \mathrm{G}$, according to reported experimental protocols. ${ }^{3,4} 10 \mu \mathrm{g}$ (400 pmol) of tRNA was preincubated for $15 \mathrm{~min}$ at $37^{\circ} \mathrm{C}$ in the following buffer with a total reaction volume of $20 \mu \mathrm{L}$ : $0.2 \mathrm{M}$ Tris-HCl buffer, $\mathrm{pH} 7.5,0.01 \mathrm{M} \mathrm{MgCl}_{2}$, and $0.2 \mathrm{M} \mathrm{KCl}$. The cooled solution was added to a freshly prepared ice-cold solution of $20 \mu \mathrm{L} \mathrm{NaBH}_{4}$ in the same buffer to give final concentrations of $60 \mu \mathrm{M}$ tRNA and $0.5 \mathrm{M} \mathrm{NaBH}_{4}$. The reduction was performed at $0{ }^{\circ} \mathrm{C}$ in an ice bath under subdued light. The reaction was terminated by pipetting aliquots of the reaction mixture into $4 \mu \mathrm{L}$ of $6 \mathrm{~N}$ acetic acid, followed by subsequent purification by Oligo Clean \& Concentrator. Then, the resulting tRNA product was dissolved in $200 \mu \mathrm{L}$ aniline/acetate solution (aniline/acetic $\mathrm{acid} /$ water $=1: 3: 7$ ), and incubated for $10 \mathrm{~min}$ at $60^{\circ} \mathrm{C} .200 \mu \mathrm{L}$ of $0.3 \mathrm{M}$ sodium acetate, $\mathrm{pH} 5.5$, was then added to the sample, followed by purification by Oligo Clean \& Concentrator for LCMS analysis. 


\section{Reverse transcription single base extension (rtSBE)}

Demethylation: The demethylation reaction was carried out at $37^{\circ} \mathrm{C}$ in $50 \mathrm{mM} \mathrm{Na-HEPES}$ buffer ( $\mathrm{pH}$ 8.0) containing $2.5 \mu \mathrm{g}(100 \mathrm{pmol})$ of tRNA, $4 \mu \mathrm{g}$ ALKBH3, a 1-methyladenosine ( $\left.{ }^{1} \mathrm{~A}\right)$ demethylase of tRNA $(2 \mu \mathrm{g} / \mu \mathrm{L}), 150 \mu \mathrm{M}$ ammonium iron (II) sulfate $\left(\mathrm{Fe}\left(\mathrm{NH}_{4}\right)_{2}\left(\mathrm{SO}_{4}\right)_{2}\right), 1 \mathrm{mM} \alpha$ ketoglutarate, $2 \mathrm{mM}$ sodium ascorbate, and $1 \mathrm{mM}$ TCEP (tris(2-carboxyethyl)phosphine) with a total reaction volume of $20 \mu \mathrm{L}$ for $1 \mathrm{hr}$. Oligo Clean \& Concentrator was applied to remove salts and excessive reactants. A control experiment was performed in the absence of ALKBH3 in order to rule out the possibility of cleavage of the tRNA template induced by hydroxyl radicals, which might be generated under Fenton-like reaction conditions (sodium ascorbate and $\mathrm{Fe}^{2+}$ ). ${ }^{5,6}$ $r t S B E$ : We designed a reverse transcriptase primer (5'-TGGTGCGAATTCTGTGGA-3'; the 3'primer end is adjacent to the $\mathrm{m}^{1} \mathrm{~A}$ position) using tRNA as a template for $\mathrm{m}^{1} \mathrm{~A}$ identification, and demethylated tRNA as the control template. The rtSBE reaction was performed in a $30 \mu \mathrm{L}$ reaction volume containing $1 \times$ SuperScript ${ }^{\mathrm{TM}}$ IV RT reaction buffer, $0.625 \mu \mathrm{g}$ (25 pmol) of tRNA template, 50 pmol primer, $2.5 \mathrm{nmol}$ ddNTPs, $5 \mathrm{mM}$ DTT (dithiothreitol), $2 \mathrm{U}$ RNase inhibitor, and $10 \mathrm{U}$ SuperScript IV reverse transcriptase at $65^{\circ} \mathrm{C}$ for $5 \mathrm{~min}$, followed by incubation on ice for $1 \mathrm{~min}$. Then, the full reverse transcription reaction was carried out in a thermal cycler $\left(25\right.$ cycles of $45^{\circ} \mathrm{C}$ for $30 \mathrm{sec}$ and $55^{\circ} \mathrm{C}$ for $1 \mathrm{~min}$ ). Finally, the reaction was inactivated by incubation at $80{ }^{\circ} \mathrm{C}$ for 10 min, followed by application of Oligo Clean \& Concentrator to remove all salts and proteins. The rtSBE products were measured on a Voyager DE matrix-assisted laser desorption/ionization (MALDI)-TOF mass spectrometer (Applied Biosystems, Foster City, USA).

\section{LC-MS analysis}

LC-MS instrument: a 6550 Q-TOF mass spectrometer coupled to a 1290 Infinity LC system equipped with a MicroAS autosampler and SurveyorMS Pump Plus HPLC (high performance liquid chromatography) system (Agilent Technologies, Santa Clara, CA, USA) (Hunter College Mass Spectrometry, NY, USA). The LC column is a $50 \mathrm{~mm} \times 2.1 \mathrm{~mm} \mathrm{C18}$ column with a particle size of $1.7 \mu \mathrm{m}$. General LC-MS conditions for analyzing tRNA sequencing ladders were the same as previously reported, ${ }^{l}$ except that the gradient used was $2-20 \%$ buffer B for $60 \mathrm{~min}$, followed by a $2 \min 90 \%$ buffer B wash step. General MS conditions for the methylated dimers were the same as previously reported ${ }^{7}$ except the following: targeted MS/MS was used and the mass range for 
MS1 was 350-3200 m/z, while the mass range for MS2 was 50-750 m/z. For the CmU dimer $\left(\mathrm{C}+\mathrm{U}+2^{\prime}\right.$-O-methyl; The 2'-O-methyl renders the phosphodiester bond between $\mathrm{C}$ and $\mathrm{U}$ nonhydrolyzable), the targeted precursor was $642.0837 \mathrm{~m} / \mathrm{z}\left(\mathrm{t}_{\mathrm{R}}=2.95 \mathrm{~min}\right)$. For the GmA dimer $\left(\mathrm{G}+\mathrm{A}+2^{\prime}\right.$-O-methyl), the target precursor was $705.1164 \mathrm{~m} / \mathrm{z}\left(\mathrm{t}_{\mathrm{R}}=3.50 \mathrm{~min}\right.$ and $\left.4.08 \mathrm{~min}\right)$, collision energy $(\mathrm{CE})=20$. LC conditions: gradient of 2-20\% MeOH for $60 \mathrm{~min}$ (buffer A: 200mM hexafluoroisopropanol (HFIP), 1.25mM triethanolamine (TEA) in water). General MS conditions

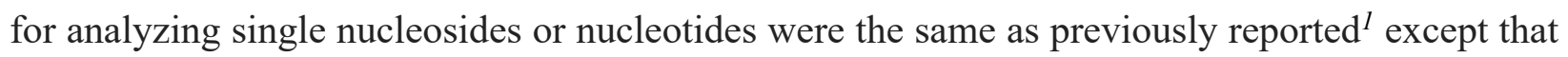
a m/z range of 100-2000 was used. LC conditions: 0\% buffer B for 5 min, 0-50\% buffer B for 30 min, $200 \mu \mathrm{L} / \mathrm{min}$ flow; buffer A: water, $0.1 \%$ formic acid and buffer B: acetonitrile (ACN), $0.1 \%$ FA; column: Waters Acquity UPLC 2.1×100 (Waters, Milford, MA, USA). The sample data was processed using the MassHunter Acquisition software (Agilent Technologies, Santa Clara, USA) with the previously described methods. The Molecular Feature Extraction (MFE) workflow in MassHunter Qualitative Analysis (Agilent Technologies, USA) was used to extract relevant spectral and chromatographic information from the LC-MS experiments as described previously. ${ }^{1}$

\section{Anchor-based algorithm with the global hierarchical ranking strategy}

The anchor-based sequencing algorithm was developed and used to process the above-mentioned MFE data. To produce RNA sequence reads from the MFE data, the algorithm typically has to go through four essential steps: data pre-processing, base-calling, draft sequence generation, and final sequence identification.

In the data pre-processing step, the original MFE dataset was subset by refining the range for both $t_{R}$ and mass value data. By this means, the algorithm focuses on reading out sequence(s) from a specific "zone" at each time, which corresponds to either a labeled or an unlabeled subset of LCMS data.

After subsetting the dataset, the algorithm performs base-calling. The theoretical mass, calculated from the chemical formula, of all known ribonucleotides, including those with modifications to the base, is stored as a list of MBASE. In the first iteration, the algorithm finds the mass corresponding to the molecular tag (anchor), e.g., the 3 '-biotin tag in the labeled subset of the MFE data, and sets $M_{\text {experimental_i }}$ equal to this mass. The algorithm tests each $\mathrm{M}_{\mathrm{BASE}}$ from the list by adding it to $\mathrm{M}_{\text {experimental_ia }}$ and generating a theoretical sum mass $\mathrm{M}_{\text {theoretical } \_ \text {. The algorithm searches }}$ through the MFE dataset for a mass value that matches with $M_{\text {theoretical } \_ \text {. If there exists a matching }}$ 


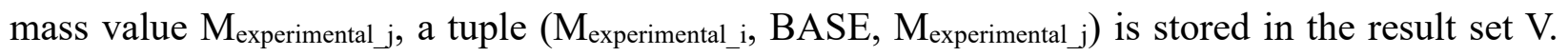
Since the algorithm tests all $\mathrm{M}_{\mathrm{BASE}}$ in the list and looks for all possible matches, multiple tuples

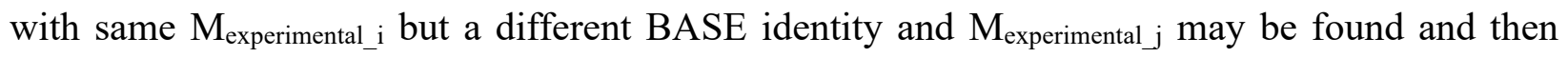
stored in set $\mathrm{V}$. When the algorithm decides if there is a match, it takes into consideration that the experimental/observed mass in the MFE data may slightly deviate from the theoretical mass for an identical ribonucleotide unit. We implemented a calculated parameter PPM (parts per million)

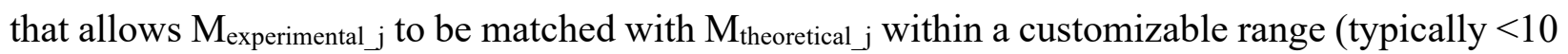
PPM).

The algorithm performs base-calling for all data points in the dataset until all possible tuples are found and stored in set $\mathrm{V}$. Note that each tuple in set V represents an individual base-calling possibility. After base-calling, the algorithm builds trajectories linking tuples in set $\mathrm{V}$ to generate draft sequence reads of the RNA.

The fourth and final step of the anchor-based algorithm is the final sequence identification. Because the outputs from LC-MS contain a large number of data points ( $>500)$, the algorithm may generate a large quantity of draft sequence reads. To effectively filter out undesired draft reads and to select the desired ones, we developed the global hierarchical ranking strategy. In this strategy, each draft read is ranked hierarchically according to the following criteria: (1) read length (the number of nucleobases in a draft read), (2) average volume, (3) average quality score (QS), and (4) average PPM. Average volume is calculated by summing the volume associated with each data point in a draft read and dividing the sum by read length. Average QS is calculated by dividing the sum of QS by read length. Average PPM is the sum of all PPM values associated with data points contained in a draft read divided by read length. In the end, the draft read with longest read length, highest average volume, highest average QS, and lowest average PPM wins over all other draft reads in the global hierarchical ranking procedure and is identified as the final sequence for the targeted RNA fragment.

Related MFE data and the anchor-based algorithm (including both the web-based sequencing application and the source code) are available upon request and were uploaded to a separate server at Github (https://github.com/rnamodifications/seqapp).

All figures and data presented are representative data of multiple experimental trials $(n \geqslant 3)$.

\section{Detection and sequencing of three CCA truncated isoforms}


When analyzing the biotinylated $3^{\prime}$-segment of the tRNA $\left(58 \mathrm{~m}^{1} \mathrm{~A}-76 \mathrm{~A}\right)$, we found there is more than one ladder that has the biotin tag as shown in Figure 3A, indicating that this segment contains more than one sequence. We searched for isoforms of segment III in the dataset as an additional step to the global hierarchical ranking algorithm. The final output (Tables S1-S3) of the original algorithm is one of the three isoforms and is aligned with all draft reads by a Smith-Waterman alignment 8 to acquire their alignment score. Draft reads with an alignment score above $94.44 \%$ are considered candidates of isoforms, and the candidates are ranked by average volume. We acquired six candidates with a threshold of $94.44 \%$. Because the only variation between the isoforms is that they have different tail lengths and sequences of $\mathrm{C}, \mathrm{CC}$, or CCA respectively, the tails of the six candidates were trimmed and a second round of Smith-Waterman alignment was executed. After trimming, draft reads of isoforms had a 100\% alignment score with each other, and thus were filtered out from the six candidates.

\section{Full-spectral analysis for a new 44g45a isoform}

To verify the co-existence of the two mass fragments (44A45G and 44g45a), we employed fullspectral analysis provided by the commercial MassWorks software (version 5.0) (Cerno Bioscience, Las Vegas, USA) to examine the corresponding ions of these two fragments simultaneously and see if they co-exist in one spectrum. MassWorks was used to process the original Agilent LC-MS data files, which was then calibrated for spectral accuracy before further analysis. When reading from the 5'-direction, two ions (m/z 778.1051 and 779.7068, both with 10 charge states) were found for $14 \mathrm{nt}$ fragments $(21 \mathrm{~A}-44 \mathrm{~A} / \mathrm{g})$ in the $t_{\mathrm{R}}$ window $\left(\mathrm{t}_{\mathrm{R}}=31.9-32.9 \mathrm{~min}\right)$ corresponding to 44A and 44g. Also, two ions (m/z 1052.6314 and 1056.6294, both with 7 charge states) were found during full-spectral analysis for $13 \mathrm{nt}$ fragments $(45 \mathrm{G} / \mathrm{a}-57 \mathrm{G})\left(\mathrm{t}_{\mathrm{R}}=16.5-18.6\right.$ min) when reading from the 3 '-direction, confirming that $45 \mathrm{G}$ and $45 \mathrm{a}$ co-exist.

\section{Stoichiometric quantification of all 11 RNA modifications}

The relative percentages of 11 modified nucleotides vs. their corresponding canonical nucleotides at each position were quantified by integrating extracted-ion current (EIC) peaks of their corresponding ladder fragments from tRNA according to the previously reported methods. ${ }^{1,8}$ These results in detail are shown in Table S19. 

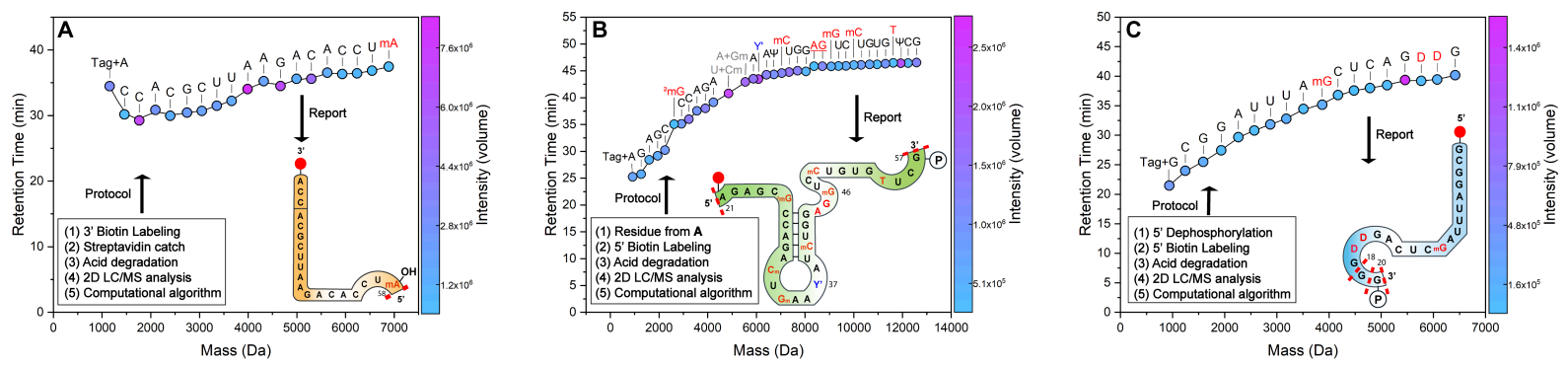

Figure S1. 2D-HELS-AA MS Seq (2-dimensional hydrophobic RNA end-labeling strategy with an anchor-based algorithm in mass spectrometry-based sequencing) of three segments digested by RNase T1. As part of HELS, based on the unique chemical moieties on the termini of the three segments, we selectively introduced a single biotin label to each of the three segments on either their $5^{\prime}$ - or their $3^{\prime}$-end followed by streptavidin bead-based isolation and release of each segment for acid degradation by formic acid. After liquid chromatography (LC)-MS and data collection, data were subsequently exported by a molecular feature extraction (MFE, Agilent, USA) algorithm for sequence generation using an anchor-based algorithm. We were able to determine a sequence of 19 bases $\left(58 \mathrm{~m}^{1} \mathrm{~A}\right.$ to 76A) corresponding to segment III (A), a sequence of 37 bases (21A to $57 \mathrm{G}$ ) corresponding to segment II (B), and a sequence of 18 bases corresponding to segment I (1G to $18 \mathrm{G})(\mathbf{C})$, respectively. We also successfully detected the location of all 11 mass-altering tRNA modifications in the three segments.
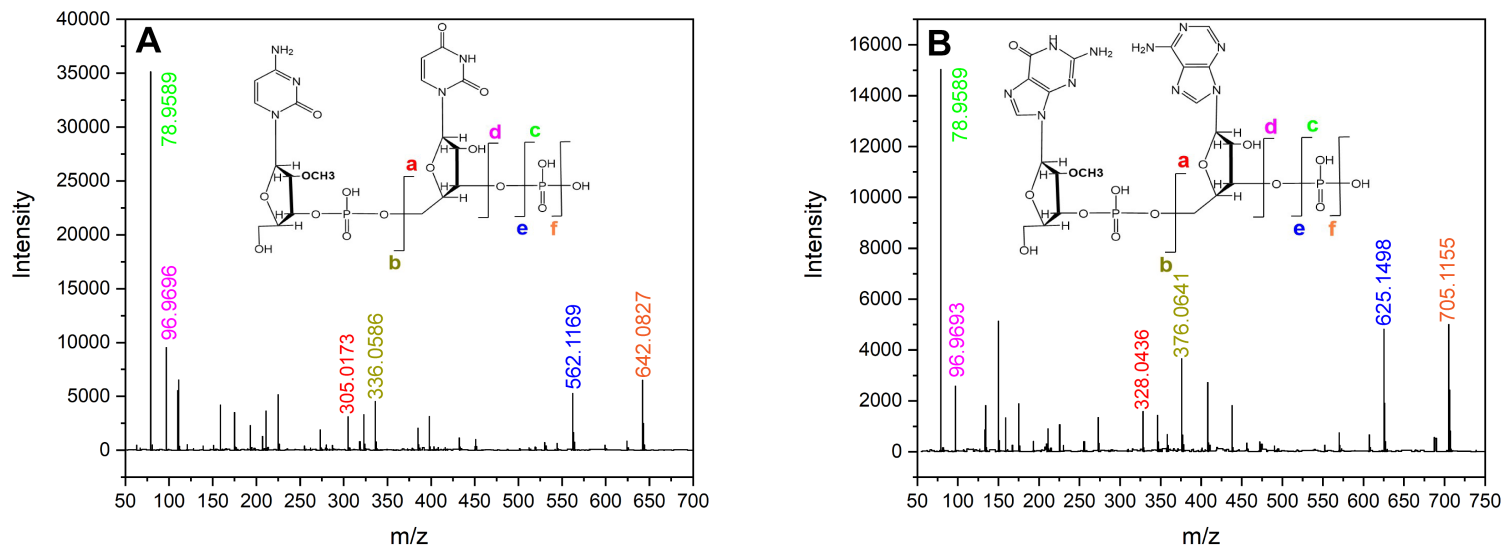

Figure S2. MS analysis of methylated nucleotide dimers by collision induced dissociation (CID) MS/MS. Samples were prepared by intensive acid hydrolysis $\left(80^{\circ} \mathrm{C}, 75 \%(\mathrm{v} / \mathrm{v})\right.$ formic acid, $\left.2 \mathrm{hrs}\right)$ to generate the dimers. MS/MS data were collected for the modified dimer and fragment ions were used to confirm that the methylation is on the ribose $2^{\prime}$ position of cytidine. The sequences are (A) $\mathrm{CmU}$ and (B) $\mathrm{GmA}$, respectively. Assignable fragment labels are indicated on the dimer structures, and the peaks representing the fragments match by color. 


\section{Reverse Transcription SBE}

tRNA Template: $3^{\prime}$-ACCACGCUUAAGACACCU $\mathrm{m}^{1} \mathrm{~A}-5^{\prime}$ RT Primer: 5 '-TGGTGCGAATTCTGTGGA $\times \mathbf{3}^{3}$

tRNA Template: $3^{\prime}$-ACCACGCUUAAGACACCU $\mathrm{m}^{6} \mathrm{~A}-5^{\circ}$ RT Primer: 5'-TGGTGCGAATTCTGTGGA $\sqrt{ }-3^{\prime}$

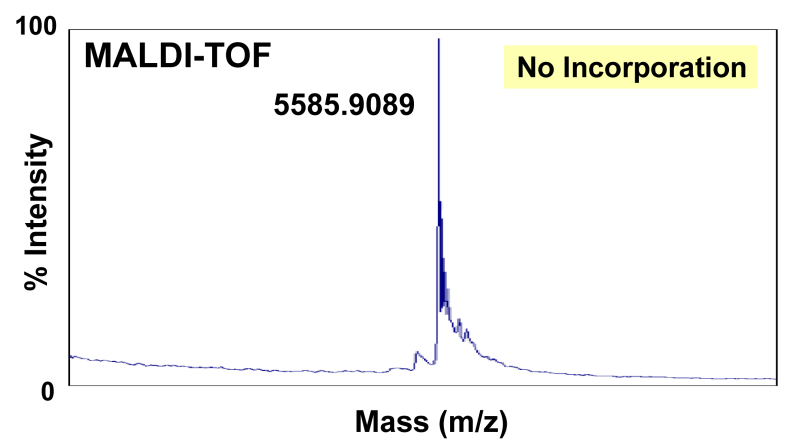

\section{Reverse Transcription SBE as Control}

\section{Demethylation by ALKBH3}

tRNA Template: $3^{\prime}$-ACCACGCUUAAGACACCU A $-5^{\circ}$ RT Primer: 5'-TGGTGCGAATTCTGTGGA ddT -3'

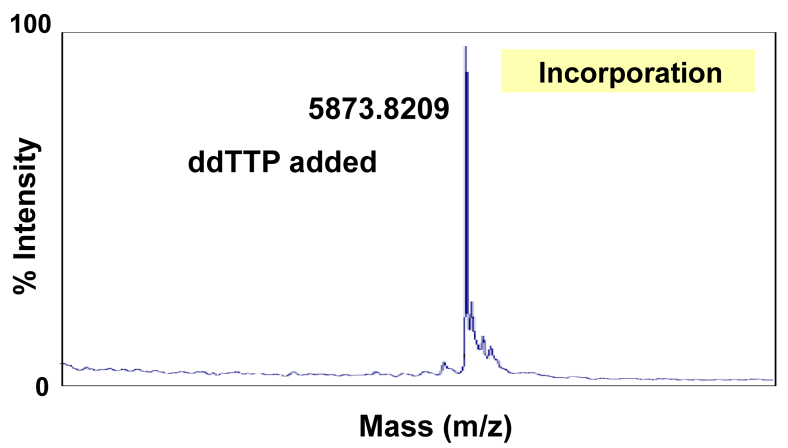

Figure S3. Reverse transcription single base extension (rtSBE) experiment to differentiate $\mathrm{m}^{1} \mathrm{~A}$ and $\mathrm{m}^{6} \mathrm{~A}\left(\mathrm{~N}^{6}\right.$ methyladenosine). A pause was observed in the rtSBE experiment, indicating that $\mathrm{m}^{1} \mathrm{~A}$, rather than $\mathrm{m}^{6} \mathrm{~A}$, exists at position 58 , because $\mathrm{m}^{1} \mathrm{~A}$ is not able to form base-pairing interactions, thus causing a pause during reverse transcription. $^{9}$
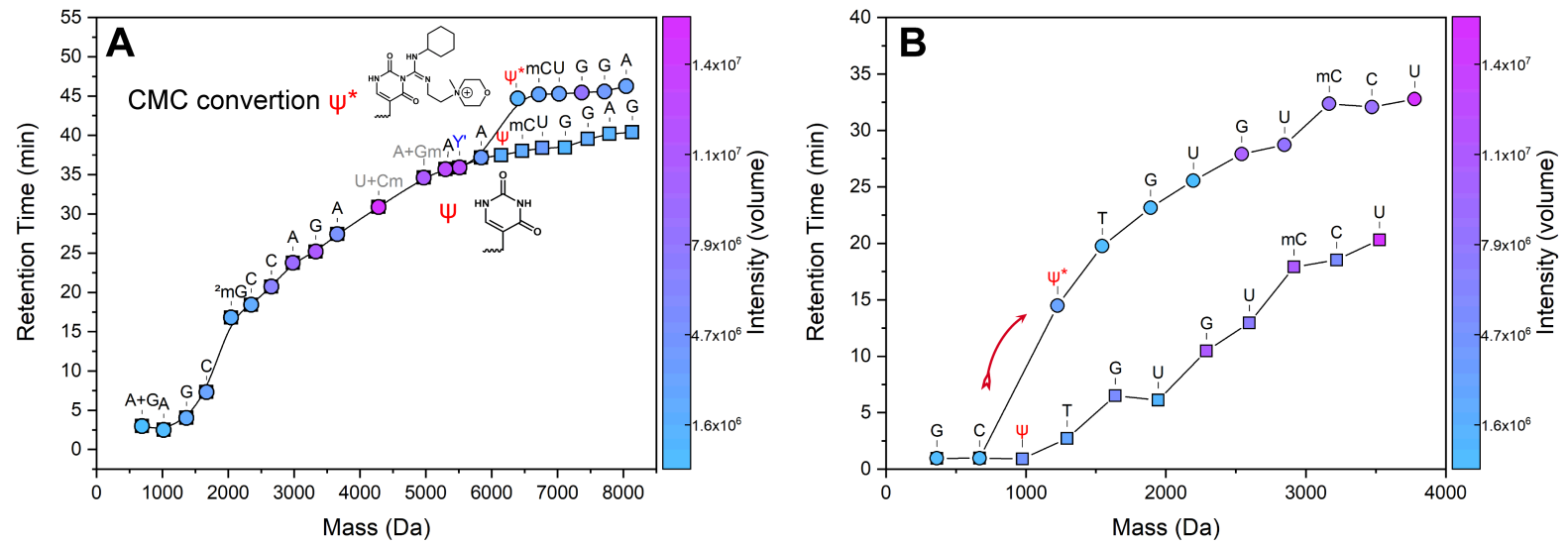

Figure S4. The conversion of pseudouridine $(\psi)$ to CMC-labeled pseudouridine $\left(\psi^{*}\right)$ results in a shift in both tR and mass of relevant data points, allowing facile identification and location of $\psi$ at this position due to a single drastic jump in the mass- $t_{R}$ ladder. For ease of visualization, only the sequences of the (A) $5^{\prime}$-mass- $t_{R}$ ladder (22G to 44A) and (B) 3'-mass-t $t_{R}$ ladder ( $57 \mathrm{G}$ to $47 \mathrm{U}$ ) are presented. The sequences presented were manually acquired based on the mass- $t_{R}$ ladders identified from the algorithm-processed data. The structures in (A) show the chemical conversion of $\psi$ by reaction with $\mathrm{CMC}$ to form the $\mathrm{CMC}-\psi$ adduct, shifting $\mathrm{CMC}-\psi$-containing mass-tR ladders in both mass and $t_{R}$ compared to mass-tr ladders containing unconverted $\psi$. 

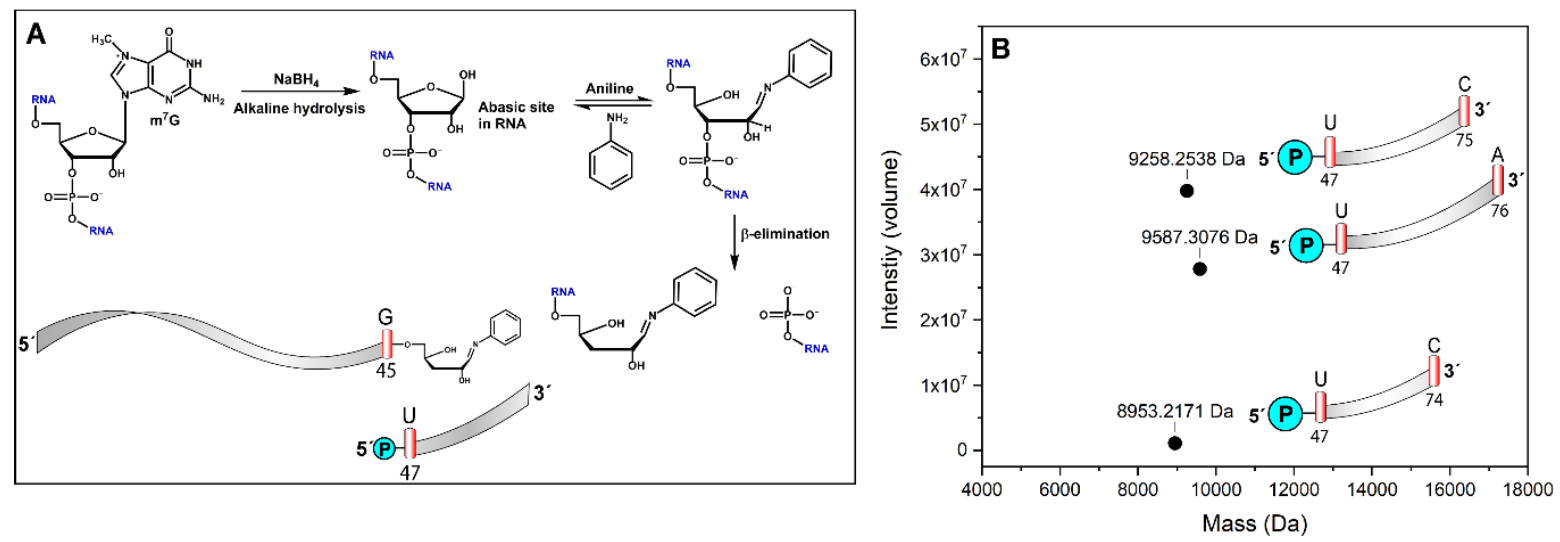

C

\begin{tabular}{|c|c|c|c|c|c|c|}
\hline Fragment & Calc mass (Da) & Exp mass (Da) & $\mathbf{m} / \mathbf{z}$ & EIC ratio & Quality score & ppm \\
\hline $47 \mathrm{U}$ to $75 \mathrm{C}$ & 9258.2251 & 9258.2538 & 711.1664 & 0.55 & 100 & -3.1 \\
\hline $47 \mathrm{U}$ to $76 \mathrm{~A}$ & 9587.2776 & 9587.3076 & 736.4783 & 0.45 & 100 & -3.1 \\
\hline
\end{tabular}

Figure S5. (A) Chemistry for distinguishing $\mathrm{m}^{7} \mathrm{G}$ from other isomeric base modifications, such as $\mathrm{m}^{2} \mathrm{G}\left(\mathrm{N}^{2}\right.$ methylguanosine), that share an identical mass. (B) The plot of Intensity vs. Mass after chemical cleavage of the RNA at $\mathrm{m}^{7} \mathrm{G}$ site-specifically. The mass of the three major fragments observed were $9587.3076 \mathrm{Da}, 9258.2538 \mathrm{Da}$, and 8953.2171 Da, corresponding to their $76 \mathrm{nt}, 75 \mathrm{nt}$, and $74 \mathrm{nt}$ isoforms, respectively, indicating that there is a $\mathrm{m}^{7} \mathrm{G}$ at the 46 position. (C) Specific fragments cleaved at $\mathrm{m}^{7} \mathrm{G}$ were analyzed by LC-MS and quantified by integrating EIC peaks of their corresponding fragments. 
4544

tRNA template: $33^{\prime}----A G A$ CAC CUA GC $\Psi$ TGU GUC CUG GA G GUC $\Psi$ AY AAG ----5"

cDNA Primer2: 5'- TC T GTG GAT CGA ACA CAG GAC C ddT - -3 '

cDNA Primer 1: 5'- TC T GTG GAT CGA ACA CAG GAC ddC
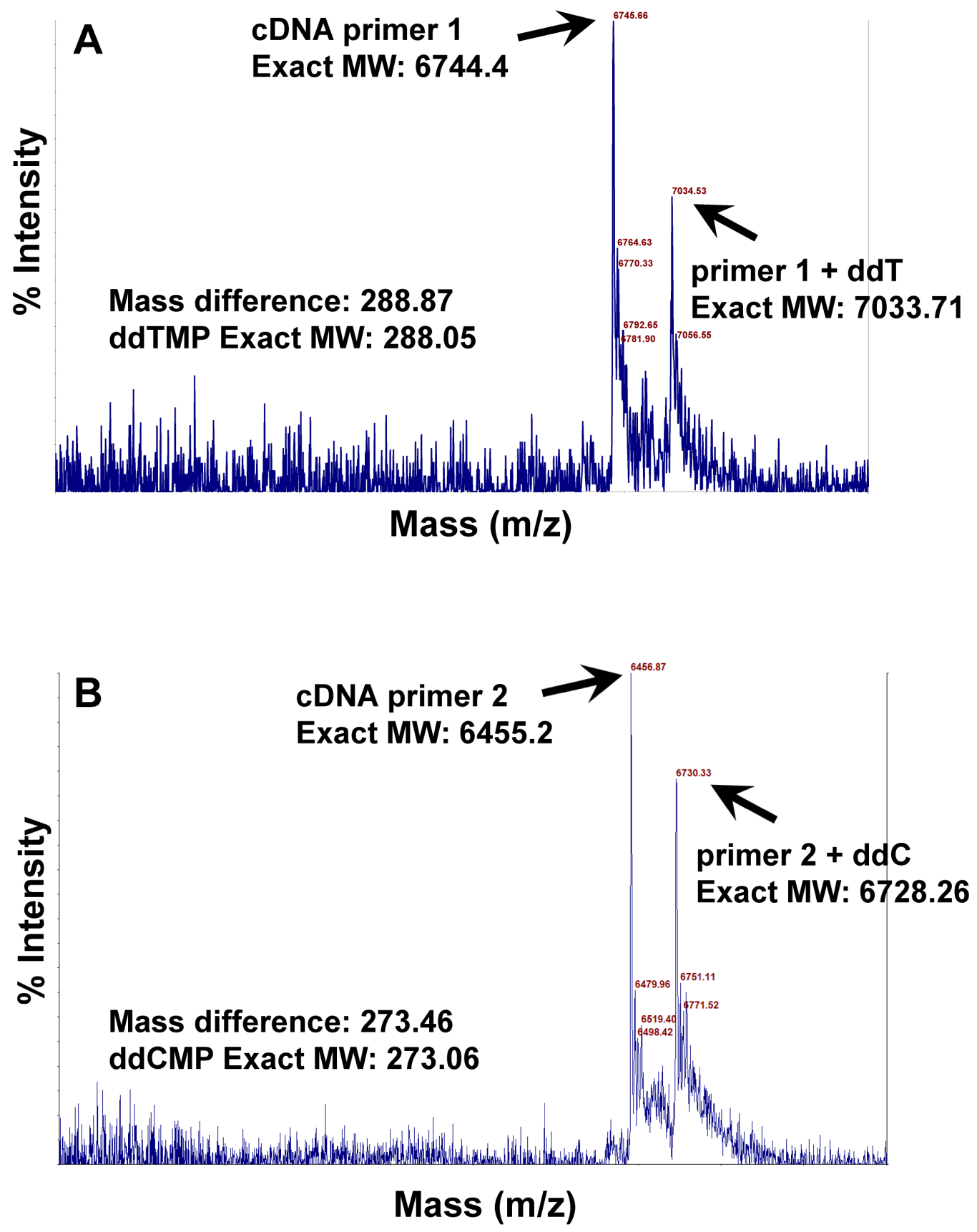

Figure S6. MALDI-TOF results of rtSBE experiments. (A) For cDNA primer 1, only ddT (position 44) was incorporated. (B) For cDNA primer 2, only ddC (position 45) was incorporated. The results suggest that the tRNA template in the rtSBE experiment was the $44 \mathrm{~A}$ and $45 \mathrm{G}$ wild-type isoform. 
A

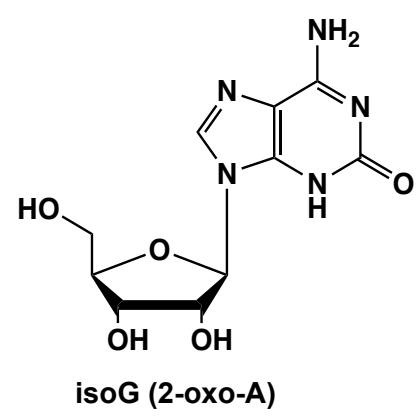

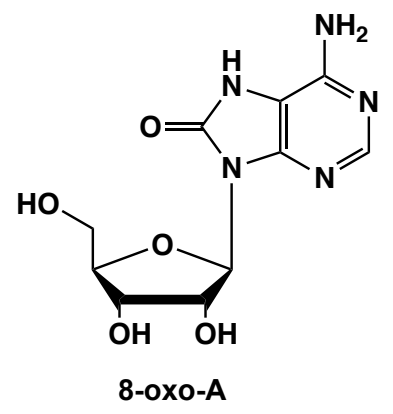

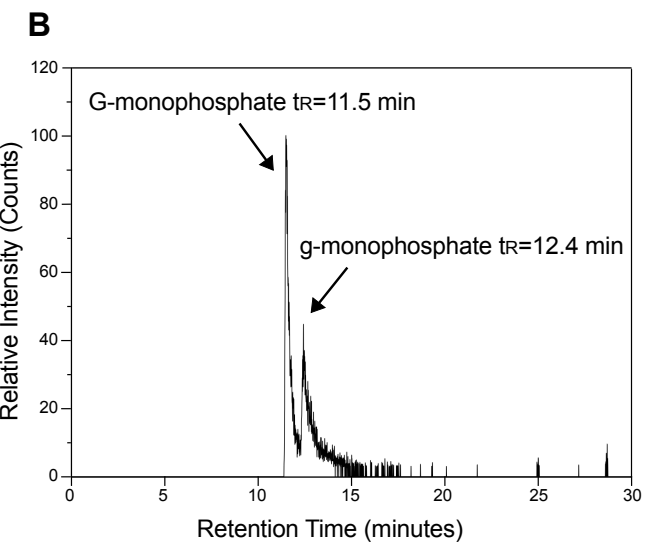

Figure S7. (A) Chemical structure of isoG (2-oxoadenine) and 8-oxo-A (8-oxoadenine). (B) The EIC profile confirms the existence of both $\mathrm{G}$ monophosphate and $\mathrm{g}$ monophosphate (lower case $\mathrm{g}$ is used to differentiate it from the canonical $\mathrm{G}$ in position 44$)$ at different $\mathrm{t}_{\mathrm{R}}$. 
Table S1. 3'_biotin_tRNA_T1_SIII_111418s05_76A. Sequencing of 3'-biotin-labeled tRNA segment III from $58 \mathrm{~m}^{1} \mathrm{~A}$ to $76 \mathrm{~A}$ using the global hierarchical ranking algorithm and a revised Smith-Waterman alignment similarity algorithm (alignment score: 95.0\%). The output sequence is indicated at the bottom.

$\begin{array}{rrrlrr}\text { Fragment } & \text { Mass } & \text { RT } & \text { Base } & \text { Volume } & \text { PPM } \\ 1 & 826.3164 & 35.809 & \text { Tag } & 2645323 & 2.42 \\ 2 & 1155.3679 & 34.555 & \mathrm{~A} & 580850 & 2.60 \\ 3 & 1460.4116 & 30.202 & \mathrm{C} & 259583 & 0.41 \\ 4 & 1765.4505 & 29.311 & \mathrm{C} & 4875476 & 1.70 \\ 5 & 2094.5027 & 30.921 & \mathrm{~A} & 560348 & 1.58 \\ 6 & 2399.5455 & 30.024 & \mathrm{C} & 241970 & 0.75 \\ 7 & 2744.5948 & 30.494 & \mathrm{G} & 365785 & 0.04 \\ 8 & 3049.6138 & 30.755 & \mathrm{C} & 245795 & 7.28 \\ 9 & 3355.6561 & 31.57 & \mathrm{U} & 377273 & 1.55 \\ 10 & 3661.6854 & 32.93 & \mathrm{U} & 4226311 & 0.33 \\ 11 & 3990.7364 & 34.122 & \mathrm{~A} & 4968527 & 0.68 \\ 12 & 4319.7918 & 35.332 & \mathrm{~A} & 245329 & 0.05 \\ 13 & 4664.8388 & 34.606 & \mathrm{G} & 4756748 & 0.04 \\ 14 & 4993.8992 & 35.504 & \mathrm{~A} & 307359 & 1.54 \\ 15 & 5298.9333 & 35.691 & \mathrm{C} & 4083332 & 0.09 \\ 16 & 5627.9522 & 35.501 & \mathrm{~A} & 160811 & 5.88 \\ 17 & 5933.0022 & 35.649 & \mathrm{C} & 157328 & 4.11 \\ 18 & 6238.0838 & 36.541 & \mathrm{C} & 89737 & 2.55 \\ 19 & 6544.1101 & 36.202 & \mathrm{U} & 672814 & 2.58 \\ 20 & 6887.1727 & 37.539 & \mathrm{~mA} & 1193510 & 1.66\end{array}$

Ts 1 Output Sequence:

5'-mAUCCACAGAAUUCGCACCA-3'

$\mathrm{mA}$ is a symbol used in the global hierarchical ranking algorithm to designate a nucleobase modification that has the same mass value as a methylated $\mathrm{A}$. 
Table S2. 3'_biotin_tRNA_T1_SIII_111418s05_75C. Sequencing of 3'-biotin-labeled tRNA segment III from $58 \mathrm{~m}^{1} \mathrm{~A}$ to $75 \mathrm{C}$ using the global hierarchical ranking algorithm and a revised Smith-Waterman alignment similarity algorithm (alignment score: 100\%). The output sequence is indicated at the bottom.

$\begin{array}{rrrlrr}\text { Fragment } & \text { Mass } & \text { RT } & \text { Base } & \text { Volume } & \text { PPM } \\ 1 & 826.3164 & 35.809 & \text { Tag } & 2645323 & 2.42 \\ 2 & 1131.3573 & 28.724 & \text { C } & 2536602 & 2.12 \\ 3 & 1436.3979 & 26.748 & \text { C } & 1504369 & 2.16 \\ 4 & 1765.4505 & 29.311 & \text { A } & 4875476 & 1.70 \\ 5 & 2070.4898 & 27.904 & \text { C } & 1807879 & 2.41 \\ 6 & 2415.5392 & 28.436 & \text { G } & 4919858 & 1.24 \\ 7 & 2720.5806 & 28.781 & \text { C } & 4403013 & 1.07 \\ 8 & 3026.6061 & 29.745 & \text { U } & 5263366 & 0.89 \\ 9 & 3332.6311 & 30.654 & \text { U } & 3654432 & 0.90 \\ 10 & 3661.6854 & 32.930 & \text { A } & 4226311 & 0.33 \\ 11 & 3990.7364 & 34.122 & \text { A } & 4968527 & 0.68 \\ 12 & 4335.7879 & 33.348 & \text { G } & 2855812 & 0.32 \\ 13 & 4664.8388 & 34.606 & \text { A } & 4756748 & 0.04 \\ 14 & 4969.8783 & 34.250 & \text { C } & 2303352 & 0.40 \\ 15 & 5298.9333 & 35.691 & \text { A } & 4083332 & 0.09 \\ 16 & 5603.9769 & 35.502 & \text { C } & 2292626 & 0.50 \\ 17 & 5909.0178 & 35.637 & \text { C } & 2429322 & 0.41 \\ 18 & 6215.0412 & 36.088 & \text { U } & 860704 & 0.08 \\ 19 & 6558.1157 & 36.751 & \mathrm{~mA} & 16787962 & 1.05\end{array}$

Ts 2 Output Sequence:

5'-mAUCCACAGAAUUCGCACC-3' 
Table S3. 3'_biotin_tRNA_T1_SIII_111418s05_74C. Sequencing of 3'-biotin-labeled tRNA segment III from $58 \mathrm{~m}^{1} \mathrm{~A}$ to $74 \mathrm{C}$ using the global hierarchical ranking algorithm and a revised Smith-Waterman alignment similarity algorithm (alignment score: 94.7\%). The output sequence is indicated at the bottom.

$\begin{array}{rrrlrr}\text { Fragment } & \text { Mass } & \text { RT } & \text { Base } & \text { Volume } & \text { PPM } \\ 1 & 826.3164 & 35.809 & \text { Tag } & 2645323 & 2.42 \\ 2 & 1131.3573 & 28.724 & \mathrm{C} & 2536602 & 2.12 \\ 3 & 1460.4116 & 30.202 & \mathrm{~A} & 259583 & 0.41 \\ 4 & 1765.4505 & 29.311 & \mathrm{C} & 4875476 & 1.70 \\ 5 & 2110.4918 & 27.882 & \mathrm{G} & 356221 & 4.31 \\ 6 & 2415.5392 & 28.436 & \mathrm{C} & 4919858 & 1.24 \\ 7 & 2721.5695 & 29.145 & \mathrm{U} & 239635 & 0.73 \\ 8 & 3027.5972 & 30.047 & \mathrm{U} & 68400 & 1.45 \\ 9 & 3356.6432 & 32.543 & \mathrm{~A} & 189932 & 0.63 \\ 10 & 3685.6934 & 33.833 & \mathrm{~A} & 159564 & 1.19 \\ 11 & 4030.7417 & 33.004 & \mathrm{G} & 82558 & 0.87 \\ 12 & 4359.8007 & 34.352 & \mathrm{~A} & 289735 & 0.69 \\ 13 & 4664.8388 & 34.606 & \mathrm{C} & 4756748 & 0.04 \\ 14 & 4993.8992 & 35.504 & \mathrm{~A} & 307359 & 1.54 \\ 15 & 5298.9333 & 35.691 & \mathrm{C} & 4083332 & 0.09 \\ 16 & 5603.9769 & 35.502 & \mathrm{C} & 2292626 & 0.50 \\ 17 & 5910.0206 & 35.639 & \mathrm{U} & 98526 & 3.59 \\ 18 & 6253.0697 & 36.605 & \mathrm{~mA} & 181155 & 0.35\end{array}$

Ts 3 Output Sequence:

5'-mAUCCACAGAAUUCGC-3' 
Table S4. 5'_OH_tRNA_T1_SII_111418s05_44A45G. Sequencing of 5'-OH tRNA segment II from $21 \mathrm{~A}$ to $57 \mathrm{G}$ by the global hierarchical ranking algorithm. The output sequence is indicated at the bottom.

$\begin{array}{rrrlrr}\text { Fragment } & \text { Mass } & \mathrm{RT} & \text { Base } & \text { Volume } & \text { PPM } \\ 1 & 692.1081 & 0.945 & \mathrm{~A}+\mathrm{G} & 448392 & 3.47 \\ 2 & 1021.1592 & 0.996 & \mathrm{~A} & 612623 & 3.72 \\ 3 & 1366.2059 & 1.023 & \mathrm{G} & 1163701 & 3.29 \\ 4 & 1671.2489 & 1.112 & \mathrm{C} & 1917190 & 1.68 \\ 5 & 2044.3269 & 8.858 & 2 \mathrm{mG} & 2025885 & 1.71 \\ 6 & 2349.3682 & 10.309 & \mathrm{C} & 3120462 & 1.49 \\ 7 & 2654.4101 & 12.749 & \mathrm{C} & 6309574 & 1.09 \\ 8 & 2983.4617 & 16.073 & \mathrm{~A} & 5462129 & 1.27 \\ 9 & 3328.5102 & 17.647 & \mathrm{G} & 6892234 & 0.81 \\ 10 & 3657.5632 & 19.875 & \mathrm{~A} & 4203490 & 0.60 \\ 11 & 4282.6476 & 23.391 & \mathrm{U}+\mathrm{Cm} & 11059167 & 0.02 \\ 12 & 4970.7632 & 26.996 & \mathrm{~A}+\mathrm{Gm} & 8957192 & 2.23 \\ 13 & 5299.8175 & 28.115 & \mathrm{~A} & 9137581 & 2.45 \\ 14 & 5511.8281 & 28.449 & \mathrm{Y} & 9044373 & 2.70 \\ 15 & 5840.8796 & 29.718 & \mathrm{~A} & 7213450 & 8.82 \\ 16 & 6146.9082 & 30.061 & \mathrm{U} & 12938074 & 8.92 \\ 17 & 6465.9647 & 30.688 & \mathrm{mC} & 6445803 & 6.50 \\ 18 & 6771.9918 & 31.161 & \mathrm{U} & 6802824 & 0.55 \\ 19 & 7117.0401 & 31.251 & \mathrm{G} & 3468612 & 0.39 \\ 20 & 7462.0865 & 32.049 & \mathrm{G} & 2834683 & 5.86 \\ 21 & 7791.1394 & 32.735 & \mathrm{~A} & 2239278 & 0.44 \\ 22 & 8136.1981 & 33.016 & \mathrm{G} & 3437631 & 0.97 \\ 23 & 8495.2645 & 33.131 & \mathrm{mG} & 2251492 & 6.91 \\ 24 & 8801.2888 & 33.439 & \mathrm{U} & 3178250 & 6.56 \\ 25 & 9106.3319 & 33.677 & \mathrm{C} & 3146668 & 7.88 \\ 26 & 9425.3892 & 33.961 & \mathrm{mC} & 3341188 & 2.50 \\ 27 & 9731.4100 & 34.135 & \mathrm{U} & 3700286 & 1.96 \\ 28 & 10076.4607 & 34.378 & \mathrm{G} & 2776140 & 2.21 \\ 29 & 10382.4798 & 34.582 & \mathrm{U} & 2849708 & 1.56 \\ 30 & 10727.5480 & 34.793 & \mathrm{G} & 2740634 & 3.45 \\ 31 & 11047.5761 & 35.136 & \mathrm{~T} & 781981 & 2.18 \\ 32 & 11353.6241 & 35.183 & \mathrm{U} & 4303300 & 4.11 \\ 33 & 11658.6776 & 35.364 & \mathrm{C} & 1498752 & 5.05 \\ 34 & 12003.6973 & 35.531 & \mathrm{G} & 6123452 & 2.60\end{array}$

Ts 4 Output Sequence:

\section{5'-AGAGC2mGCCAGACmUGmAAY'AUmCUGGAGmGUCmCUGUGTUCG-3'}

$2 \mathrm{mG}, \mathrm{Gm}$, and $\mathrm{mG}$ are symbols used in the global hierarchical ranking algorithm to designate $\mathrm{m}^{2}{ }_{2} \mathrm{G}\left(\mathrm{N}^{2}, \mathrm{~N}^{2}\right.$-dimethylguanosine), 2'-O-methylated $\mathrm{G}$, and a nucleobase modification that has the same mass value as a methylated $\mathrm{G}$ (such as $\mathrm{m}^{2} \mathrm{G}$ and $\mathrm{m}^{7} \mathrm{G}$ ), respectively. 
Table S5. 5'_OH_tRNA_T1_SII_111418s05_44g45a. Sequencing of 5'-OH tRNA segment II from $21 \mathrm{~A}$ to $57 \mathrm{G}$ by the global hierarchical ranking algorithm. The output sequence is indicated at the bottom.

$\begin{array}{rrrlrr}\text { Fragment } & \text { Mass } & \mathrm{RT} & \text { Base } & \text { Volume } & \text { PPM } \\ 1 & 692.1081 & 0.945 & \mathrm{~A}+\mathrm{G} & 448392 & 3.47 \\ 2 & 1021.1592 & 0.996 & \mathrm{~A} & 612623 & 3.72 \\ 3 & 1366.2059 & 1.023 & \mathrm{G} & 1163701 & 3.29 \\ 4 & 1671.2489 & 1.112 & \mathrm{C} & 1917190 & 1.68 \\ 5 & 2044.3269 & 8.858 & 2 \mathrm{mG} & 2025885 & 1.71 \\ 6 & 2349.3682 & 10.309 & \mathrm{C} & 3120462 & 1.49 \\ 7 & 2654.4101 & 12.749 & \mathrm{C} & 6309574 & 1.09 \\ 8 & 2983.4617 & 16.073 & \mathrm{~A} & 5462129 & 1.27 \\ 9 & 3328.5102 & 17.647 & \mathrm{G} & 6892234 & 0.81 \\ 10 & 3657.5632 & 19.875 & \mathrm{~A} & 4203490 & 0.60 \\ 11 & 4282.6476 & 23.391 & \mathrm{U}+\mathrm{Cm} & 11059167 & 0.02 \\ 12 & 4970.7632 & 26.996 & \mathrm{~A}+\mathrm{Gm} & 8957192 & 2.23 \\ 13 & 5299.8175 & 28.115 & \mathrm{~A} & 9137581 & 2.45 \\ 14 & 5511.8281 & 28.449 & \mathrm{Y} & 9044373 & 2.70 \\ 15 & 5840.8796 & 29.718 & \mathrm{~A} & 7213450 & 8.82 \\ 16 & 6146.9082 & 30.061 & \mathrm{U} & 12938074 & 8.92 \\ 17 & 6465.9647 & 30.688 & \mathrm{mC} & 6445803 & 6.50 \\ 18 & 6771.9918 & 31.161 & \mathrm{U} & 6802824 & 0.55 \\ 19 & 7117.0401 & 31.251 & \mathrm{G} & 3468612 & 0.39 \\ 20 & 7462.0865 & 32.049 & \mathrm{G} & 2834683 & 5.86 \\ 21 & 7807.1332 & 32.101 & \mathrm{G} & 2248564 & 5.51 \\ 22 & 8136.1981 & 33.016 & \mathrm{~A} & 3437631 & 6.81 \\ 23 & 8495.2645 & 33.131 & \mathrm{mG} & 2251492 & 6.91 \\ 24 & 8801.2888 & 33.439 & \mathrm{U} & 3178250 & 6.56 \\ 25 & 9106.3319 & 33.677 & \mathrm{C} & 3146668 & 7.88 \\ 26 & 9425.3892 & 33.961 & \mathrm{mC} & 3341188 & 2.50 \\ 27 & 9731.4100 & 34.135 & \mathrm{U} & 3700286 & 1.96 \\ 28 & 10076.4607 & 34.378 & \mathrm{G} & 2776140 & 2.21 \\ 29 & 10382.4798 & 34.582 & \mathrm{U} & 2849708 & 1.56 \\ 30 & 10727.5480 & 34.793 & \mathrm{G} & 2740634 & 3.45 \\ 31 & 11047.5761 & 35.136 & \mathrm{~T} & 781981 & 2.18 \\ 32 & 11353.6241 & 35.183 & \mathrm{U} & 4303300 & 4.11 \\ 33 & 11658.6776 & 35.364 & \mathrm{C} & 1498752 & 5.05 \\ 34 & 12003.6973 & 35.531 & \mathrm{G} & 6123452 & 2.60\end{array}$

Ts 5 Output Sequence:

5'-AGAGC2mGCCAGACmUGmAAY'AUmCUGGGAmGUCmCUGUGTUCG-3'

$\mathrm{mC}$ is a symbol used in the global hierarchical ranking algorithm to designate a nucleobase modification that has the same mass value as a methylated $\mathrm{C}$. 
Table S6. 5' $5^{\prime}$ G_tRNA_T1_SI_111418s05. Sequencing of 5' $-\mathrm{pG}$ tRNA segment I from $1 \mathrm{G}$ to $20 \mathrm{G}$ by the global hierarchical ranking algorithm. The output sequence is indicated at the bottom.

$\begin{array}{rrrlrr}\text { Fragment } & \text { Mass } & \text { RT } & \text { Base } & \text { Volume } & \text { PPM } \\ 1 & 443.0222 & 0.968 & \text { pG } & 32204 & 4.74 \\ 2 & 748.0626 & 0.935 & \mathrm{C} & 327973 & 4.01 \\ 3 & 1093.1092 & 0.963 & \mathrm{G} & 247078 & 3.48 \\ 4 & 1438.1583 & 1.010 & \mathrm{G} & 1953624 & 1.46 \\ 5 & 1767.2105 & 2.512 & \mathrm{~A} & 6646248 & 1.36 \\ 6 & 2073.2377 & 4.800 & \mathrm{U} & 11078570 & 0.24 \\ 7 & 2379.2611 & 7.664 & \mathrm{U} & 13653044 & 1.01 \\ 8 & 2685.2874 & 9.948 & \mathrm{U} & 13651928 & 0.52 \\ 9 & 3014.3399 & 13.244 & \mathrm{~A} & 8446589 & 0.46 \\ 10 & 3373.3974 & 16.657 & \mathrm{MG} & 5400820 & 2.08 \\ 11 & 3678.4462 & 17.883 & \mathrm{C} & 6427287 & 0.14 \\ 12 & 3984.4711 & 19.330 & \mathrm{U} & 10498687 & 0.03 \\ 13 & 4289.5141 & 20.432 & \mathrm{C} & 13067020 & 0.42 \\ 14 & 4618.5661 & 22.240 & \mathrm{~A} & 9336602 & 0.28 \\ 15 & 4963.6167 & 23.110 & \mathrm{G} & 19445698 & 0.91 \\ 16 & 5271.6368 & 23.792 & \mathrm{D} & 6241383 & 3.11 \\ 17 & 5579.6992 & 24.454 & \mathrm{D} & 7740033 & 0.90 \\ 18 & 5924.7535 & 25.268 & \mathrm{G} & 104745696 & 2.01 \\ 19 & 6269.8003 & 25.980 & \mathrm{G} & 3057757 & 1.80 \\ 20 & 6614.8364 & 26.615 & \mathrm{G} & 673220 & 0.00\end{array}$

Ts 6 Output Sequence:

5'-GCGGAUUUAmGCUCAGDDGGG-3'

D: dihydrouridine 
Table S7. 5' biotin_tRNA_T1_SI_042519s07. Sequencing of 5'-biotin-labeled tRNA segment I from $1 \mathrm{G}$ to $18 \mathrm{G}$ by the global hierarchical ranking algorithm. The output sequence is indicated at the bottom.

$\begin{array}{rrrlrr}\text { Fragment } & \text { Mass } & \text { RT } & \text { Base } & \text { Volume } & \text { PPM } \\ 1 & 938.2184 & 21.449 & \text { Tag+G } & 403806 & 3.41 \\ 2 & 1243.2600 & 23.971 & \mathrm{C} & 277726 & 2.33 \\ 3 & 1588.3060 & 25.493 & \mathrm{G} & 238503 & 2.71 \\ 4 & 1933.3518 & 27.433 & \mathrm{G} & 44902 & 3.05 \\ 5 & 2262.4042 & 29.682 & \mathrm{~A} & 35264 & 2.65 \\ 6 & 2568.4387 & 30.807 & \mathrm{U} & 64428 & 1.25 \\ 7 & 2874.4631 & 31.835 & \mathrm{U} & 219666 & 0.80 \\ 8 & 3180.4871 & 32.783 & \mathrm{U} & 173234 & 0.31 \\ 9 & 3509.5467 & 34.465 & \mathrm{~A} & 67573 & 2.31 \\ 10 & 3868.6148 & 35.174 & \mathrm{mG} & 226704 & 3.39 \\ 11 & 4173.6443 & 36.794 & \mathrm{C} & 63409 & 0.31 \\ 12 & 4479.6520 & 37.559 & \mathrm{U} & 12772 & 3.64 \\ 13 & 4784.7078 & 38.002 & \mathrm{C} & 14478 & 0.38 \\ 14 & 5113.7758 & 38.479 & \mathrm{~A} & 69348 & 2.68 \\ 15 & 5458.8177 & 39.347 & \mathrm{G} & 1588901 & 1.50 \\ 16 & 5766.8095 & 39.208 & \mathrm{D} & 25595 & 7.11 \\ 17 & 6074.9000 & 39.440 & \mathrm{D} & 118414 & 1.40 \\ 18 & 6419.9573 & 40.140 & \mathrm{G} & 383672 & 2.87\end{array}$

Ts 7 Output Sequence:

5'-GCGGAUUUAmGCUCAGDDG-3' 
Table S8. 5'_biotin_tRNA_T1_SII_032919s07_44A45G. Sequencing of 5'-biotin-labeled segment II from $21 \mathrm{~A}$ to $57 \mathrm{G}$ by the global hierarchical ranking algorithm. The output sequence is indicated at the bottom.

$\begin{array}{rrrlrr}\text { Fragment } & \text { Mass } & \text { RT } & \text { Base } & \text { Volume } & \text { PPM } \\ 1 & 922.2241 & 25.229 & \text { Tag+A } & 745215 & 3.04 \\ 2 & 1267.2710 & 25.756 & \mathrm{G} & 577150 & 2.60 \\ 3 & 1596.3229 & 28.405 & \mathrm{~A} & 472089 & 2.44 \\ 4 & 1941.3702 & 29.167 & \mathrm{G} & 591742 & 2.06 \\ 5 & 2246.4125 & 30.221 & \mathrm{C} & 930358 & 1.34 \\ 6 & 2619.4912 & 35.055 & 2 \mathrm{mG} & 276858 & 1.15 \\ 7 & 2924.5312 & 35.109 & \mathrm{C} & 937840 & 1.47 \\ 8 & 3229.5745 & 35.989 & \mathrm{C} & 1389357 & 0.71 \\ 9 & 3558.6244 & 37.535 & \mathrm{~A} & 944505 & 1.38 \\ 10 & 3903.6768 & 38.016 & \mathrm{G} & 1334405 & 0.03 \\ 11 & 4232.7261 & 39.120 & \mathrm{~A} & 899666 & 0.73 \\ 12 & 4857.8097 & 40.778 & \mathrm{U}+\mathrm{Cm} & 2369525 & 0.37 \\ 13 & 5545.9261 & 42.941 & \mathrm{~A}+\mathrm{Gm} & 1777156 & 0.18 \\ 14 & 5874.9889 & 43.512 & \mathrm{~A} & 1527490 & 1.58 \\ 15 & 6086.9945 & 43.461 & \mathrm{Y} & 2278504 & 1.03 \\ 16 & 6416.0477 & 44.268 & \mathrm{~A} & 1366254 & 1.09 \\ 17 & 6722.0827 & 44.327 & \mathrm{U} & 1049995 & 2.48 \\ 18 & 7041.1313 & 44.591 & \mathrm{mC} & 1297495 & 1.19 \\ 19 & 7347.1602 & 44.775 & \mathrm{U} & 1560416 & 1.63 \\ 20 & 7692.2118 & 45.013 & \mathrm{G} & 1319384 & 2.11 \\ 21 & 8037.2549 & 45.410 & \mathrm{G} & 1009813 & 1.48 \\ 22 & 8366.3413 & 45.858 & \mathrm{~A} & 271843 & 5.47 \\ 23 & 8711.3823 & 45.865 & \mathrm{G} & 1226283 & 4.52 \\ 24 & 9070.4677 & 45.822 & \mathrm{mG} & 520562 & 6.80 \\ 25 & 9376.4389 & 45.871 & \mathrm{U} & 416614 & 0.81 \\ 26 & 9681.5649 & 45.921 & \mathrm{C} & 587268 & 9.54 \\ 27 & 10000.5521 & 46.069 & \mathrm{mC} & 504658 & 2.27 \\ 28 & 10306.6258 & 46.099 & \mathrm{U} & 925998 & 6.90 \\ 29 & 10651.5989 & 46.183 & \mathrm{G} & 672326 & 0.31 \\ 30 & 10957.6318 & 46.200 & \mathrm{U} & 320227 & 0.39 \\ 31 & 11302.6636 & 46.313 & \mathrm{G} & 962623 & 1.00 \\ 32 & 11622.6493 & 46.492 & \mathrm{~T} & 325162 & 8.85 \\ 33 & 11928.6903 & 46.401 & \mathrm{U} & 2182861 & 4.27 \\ 34 & 12233.7642 & 46.449 & \mathrm{C} & 463444 & 1.50 \\ 35 & 12578.8603 & 46.548 & \mathrm{G} & 2766678 & 0.47\end{array}$

Ts 8 Output Sequence:

5'-AGAGC2mGCCAGACmUGmAAY'AUmCUGGAGmGUCmCUGUGTUCG-3'

$\mathrm{Y}^{\prime}$ : a depurination product (ribose form) of the wybutosine (Y) at position 37. 
Table S9. 5'_biotin_tRNA_T1_SII_032919s07_44g45a. Sequencing of 5'-biotin-labeled tRNA segment II from $21 \mathrm{~A}$ to $57 \mathrm{G}$ by the global hierarchical ranking algorithm. The output sequence is indicated at the bottom.

$\begin{array}{rrrlrr}\text { Fragment } & \text { Mass } & \text { RT } & \text { Base } & \text { Volume } & \text { PPM } \\ 1 & 922.2241 & 25.229 & \text { Tag+A } & 745215 & 3.04 \\ 2 & 1267.2710 & 25.756 & \text { G } & 577150 & 2.60 \\ 3 & 1596.3229 & 28.405 & \mathrm{~A} & 472089 & 2.44 \\ 4 & 1941.3702 & 29.167 & \mathrm{G} & 591742 & 2.06 \\ 5 & 2246.4125 & 30.221 & \mathrm{C} & 930358 & 1.34 \\ 6 & 2619.4912 & 35.055 & 2 \mathrm{mG} & 276858 & 1.15 \\ 7 & 2924.5312 & 35.109 & \mathrm{C} & 937840 & 1.47 \\ 8 & 3229.5745 & 35.989 & \mathrm{C} & 1389357 & 0.71 \\ 9 & 3558.6244 & 37.535 & \mathrm{~A} & 944505 & 1.38 \\ 10 & 3903.6768 & 38.016 & \mathrm{G} & 1334405 & 0.03 \\ 11 & 4232.7261 & 39.120 & \mathrm{~A} & 899666 & 0.73 \\ 12 & 4857.8097 & 40.778 & \mathrm{U}+\mathrm{Cm} & 2369525 & 0.37 \\ 13 & 5545.9261 & 42.941 & \mathrm{~A}+\mathrm{Gm} & 1777156 & 0.18 \\ 14 & 5874.9889 & 43.512 & \mathrm{~A} & 1527490 & 1.58 \\ 15 & 6086.9945 & 43.461 & \mathrm{Y} & 2278504 & 1.03 \\ 16 & 6416.0477 & 44.268 & \mathrm{~A} & 1366254 & 1.09 \\ 17 & 6722.0827 & 44.327 & \mathrm{U} & 1049995 & 2.48 \\ 18 & 7041.1313 & 44.591 & \mathrm{mC} & 1297495 & 1.19 \\ 19 & 7347.1602 & 44.775 & \mathrm{U} & 1560416 & 1.63 \\ 20 & 7692.2118 & 45.013 & \mathrm{G} & 1319384 & 2.11 \\ 21 & 8037.2549 & 45.410 & \mathrm{G} & 1009813 & 1.48 \\ 22 & 8382.2778 & 45.275 & \mathrm{G} & 200964 & 1.49 \\ 23 & 8711.3823 & 45.865 & \mathrm{~A} & 1226283 & 4.51 \\ 24 & 9070.4677 & 45.822 & \mathrm{mG} & 520562 & 6.80 \\ 25 & 9376.4389 & 45.871 & \mathrm{U} & 416614 & 0.81 \\ 26 & 9681.5649 & 45.921 & \mathrm{C} & 587268 & 9.54 \\ 27 & 10000.5521 & 46.069 & \mathrm{mC} & 504658 & 2.27 \\ 28 & 10306.6258 & 46.099 & \mathrm{U} & 925998 & 6.90 \\ 29 & 10651.5989 & 46.183 & \mathrm{G} & 672326 & 0.31 \\ 30 & 10957.6318 & 46.200 & \mathrm{U} & 320227 & 0.39 \\ 31 & 11302.6636 & 46.313 & \mathrm{G} & 962623 & 1.00 \\ 32 & 11622.6493 & 46.492 & \mathrm{~T} & 325162 & 8.85 \\ 33 & 11928.6903 & 46.401 & \mathrm{U} & 2182861 & 4.27 \\ 34 & 12233.7642 & 46.449 & \mathrm{C} & 463444 & 1.50 \\ 35 & 12578.8603 & 46.548 & \mathrm{G} & 2766678 & 0.47\end{array}$

Ts 9 Output Sequence:

5'-AGAGC2mGCCAGACmUGmAAY'AUmCUGGGAmGUCmCUGUGTUCG-3' 
Table S10. 3' tRNA_100918s06. Sequencing of acid degraded tRNA from 45G to 76A by the global hierarchical ranking algorithm. The output sequence is indicated at the bottom.

$\begin{array}{rrrlrr}\text { Fragment } & \text { Mass } & \text { RT } & \text { Base } & \text { Volume } & \text { PPM } \\ 1 & 877.1786 & 1.270 & \text { A+C+C } & 1022495 & 0.91 \\ 2 & 1206.2286 & 2.926 & \mathrm{~A} & 1172115 & 2.74 \\ 3 & 1511.2689 & 2.572 & \mathrm{C} & 819385 & 2.85 \\ 4 & 1856.3153 & 3.218 & \mathrm{G} & 1266301 & 2.86 \\ 5 & 2161.3551 & 3.798 & \mathrm{C} & 1544446 & 3.15 \\ 6 & 2467.3789 & 4.806 & \mathrm{U} & 2083726 & 3.36 \\ 7 & 2773.4042 & 6.085 & \mathrm{U} & 3053673 & 2.99 \\ 8 & 3102.4553 & 7.075 & \mathrm{~A} & 5583907 & 3.13 \\ 9 & 3431.5054 & 7.910 & \mathrm{~A} & 2247902 & 3.53 \\ 10 & 3776.5516 & 7.745 & \mathrm{G} & 5639286 & 3.52 \\ 11 & 4105.6016 & 8.447 & \mathrm{~A} & 2679354 & 3.85 \\ 12 & 4410.6408 & 8.523 & \mathrm{C} & 4702025 & 4.06 \\ 13 & 4739.6917 & 9.123 & \mathrm{~A} & 2963739 & 4.11 \\ 14 & 5044.7319 & 9.175 & \mathrm{C} & 2073512 & 4.08 \\ 15 & 5349.7949 & 9.288 & \mathrm{C} & 1906782 & 0.21 \\ 16 & 5655.7967 & 9.545 & \mathrm{U} & 914935 & 3.96 \\ 17 & 5998.8627 & 9.818 & \mathrm{~mA} & 2160204 & 4.08 \\ 18 & 6343.9049 & 9.900 & \mathrm{G} & 2309111 & 4.68 \\ 19 & 6648.9464 & 9.893 & \mathrm{C} & 3092250 & 4.45 \\ 20 & 6954.9754 & 9.838 & \mathrm{U} & 1201050 & 3.72 \\ 21 & 7275.0127 & 10.396 & \mathrm{~T} & 2267279 & 4.07 \\ 22 & 7620.0765 & 10.498 & \mathrm{G} & 1762814 & 1.73 \\ 23 & 7926.1455 & 10.423 & \mathrm{U} & 1562423 & 3.85 \\ 24 & 8271.1067 & 10.603 & \mathrm{G} & 1920966 & 6.73 \\ 25 & 8577.2011 & 10.660 & \mathrm{U} & 1709835 & 1.56 \\ 26 & 8896.1598 & 11.550 & \mathrm{mC} & 875226 & 9.53 \\ 27 & 9201.2581 & 11.313 & \mathrm{C} & 769527 & 3.02 \\ 28 & 9507.2765 & 11.082 & \mathrm{U} & 572956 & 3.65 \\ 29 & 9866.3028 & 11.030 & \mathrm{mG} & 412887 & 7.25 \\ 30 & 10211.3522 & 11.073 & \mathrm{G} & 709961 & 6.81\end{array}$

Ts 10 Output Sequence:

5'-GmGUCmCUGUGTUCGmAUCCACAGAAUUCGCACCA-3' 


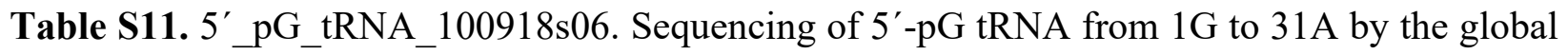
hierarchical ranking algorithm. The output sequence is indicated at the bottom.

$\begin{array}{rrrlrr}\text { Fragment } & \text { Mass } & \text { RT } & \text { Base } & \text { Volume } & \text { PPM } \\ 1 & 443.0274 & 0.931 & \text { pG } & 233231 & 7.00 \\ 2 & 748.0684 & 1.039 & \mathrm{C} & 883929 & 3.74 \\ 3 & 1093.1105 & 1.800 & \mathrm{G} & 2062278 & 2.29 \\ 4 & 1438.1575 & 3.239 & \mathrm{G} & 3687690 & 2.02 \\ 5 & 1767.2087 & 4.484 & \mathrm{~A} & 4522172 & 2.38 \\ 6 & 2073.2354 & 5.369 & \mathrm{U} & 8131266 & 1.35 \\ 7 & 2379.2590 & 6.043 & \mathrm{U} & 8862830 & 1.89 \\ 8 & 2685.2836 & 6.593 & \mathrm{U} & 9612100 & 1.94 \\ 9 & 3014.3343 & 7.355 & \mathrm{~A} & 6218090 & 2.32 \\ 10 & 3373.3964 & 8.120 & \mathrm{mG} & 2974994 & 2.37 \\ 11 & 3678.4380 & 8.403 & \mathrm{C} & 3957178 & 2.09 \\ 12 & 3984.4601 & 8.709 & \mathrm{U} & 6419872 & 2.74 \\ 13 & 4289.5007 & 8.942 & \mathrm{C} & 8348561 & 2.70 \\ 14 & 4618.5517 & 9.346 & \mathrm{~A} & 3797284 & 2.84 \\ 15 & 4963.6043 & 9.522 & \mathrm{G} & 217686 & 1.59 \\ 16 & 5271.6374 & 9.631 & \mathrm{D} & 3108073 & 3.00 \\ 17 & 5579.6773 & 9.748 & \mathrm{D} & 3781679 & 3.03 \\ 18 & 5924.7327 & 9.944 & \mathrm{G} & 689750 & 1.50 \\ 19 & 6269.7714 & 10.091 & \mathrm{G} & 2753572 & 2.81 \\ 20 & 6614.8124 & 10.232 & \mathrm{G} & 1506355 & 3.63 \\ 21 & 6943.8650 & 10.468 & \mathrm{~A} & 1708708 & 3.44 \\ 22 & 7288.9012 & 10.601 & \mathrm{G} & 779104 & 4.82 \\ 23 & 7617.9417 & 10.826 & \mathrm{~A} & 852001 & 6.18 \\ 24 & 7963.0075 & 10.910 & \mathrm{G} & 2445671 & 3.60 \\ 25 & 8268.0027 & 11.143 & \mathrm{C} & 1087860 & 9.05 \\ 26 & 8641.1310 & 11.694 & 2 \mathrm{mG} & 207499 & 2.92 \\ 27 & 8946.1664 & 11.727 & \mathrm{C} & 1364582 & 1.86 \\ 28 & 9251.2074 & 11.743 & \mathrm{C} & 1059830 & 1.76 \\ 29 & 9580.2455 & 11.864 & \mathrm{~A} & 1450228 & 0.20 \\ 30 & 9925.3349 & 11.871 & \mathrm{G} & 2494820 & 4.42 \\ 31 & 10254.2927 & 11.993 & \mathrm{~A} & 155606 & 4.95\end{array}$

Ts 11 Output Sequence:

5'-GCGGAUUUAmGCUCAGDDGGGAGAGC2mGCCAGA-3' 
Table S12. Yield of CMC conversion occurring at pseudouridine measured by LC-MS.

\begin{tabular}{|c|c|c|c|c|c|c|c|c|}
\hline Conversion state & Fragment & Calc mass (Da) & Exp mass (Da) & $\mathbf{m} / \mathbf{z}$ & EIC ratio & QS & Yield & ppm \\
\hline Non-converted & $21 \mathrm{~A}$ to $44 \mathrm{~A}$ & 7791.1320 & 7791.1787 & 778.1111 & 0.21 & 80 & \multirow{2}{*}{$79 \%$} & -5.99 \\
\hline CMC-converted & $21 \mathrm{~A}$ to $44 \mathrm{~A}$ & 8042.3318 & 8042.3492 & 803.2263 & 0.79 & 80 & & -2.16 \\
\hline Non-converted & $57 \mathrm{G}$ to $47 \mathrm{U}$ & 3526.4344 & 3526.4333 & 586.7314 & 0.24 & 100 & \multirow{2}{*}{$76 \%$} & 0.31 \\
\hline CMC-converted & $57 \mathrm{G}$ to $47 \mathrm{U}$ & 3777.6342 & 3777.6332 & 628.5979 & 0.76 & 100 & & 0.26 \\
\hline
\end{tabular}


Table S13. 5'tRNA_T1_nonCMC_SII_042519s04_44A45G. Sequencing of 5'-non-CMCconverted tRNA segment II from $21 \bar{A}$ to $45 \mathrm{G}$ by the global hierarchical ranking algorithm. The output sequence is indicated at the bottom.

$\begin{array}{rrrlrr}\text { Fragment } & \text { Mass } & \text { RT } & \text { Base } & \text { Volume } & \text { PPM } \\ 1 & 692.1076 & 1.032 & \mathrm{~A}+\mathrm{G} & 121835 & 4.19 \\ 2 & 1021.1576 & 1.264 & \mathrm{~A} & 548483 & 5.29 \\ 3 & 1366.2072 & 4.020 & \mathrm{G} & 2219430 & 2.34 \\ 4 & 1671.2480 & 7.304 & \mathrm{C} & 3142702 & 2.21 \\ 5 & 2044.3269 & 16.800 & 2 \mathrm{mG} & 1700693 & 1.71 \\ 6 & 2349.3689 & 18.430 & \mathrm{C} & 2431764 & 1.19 \\ 7 & 2654.4105 & 20.727 & \mathrm{C} & 6691067 & 0.94 \\ 8 & 2983.4639 & 23.756 & \mathrm{~A} & 9276684 & 0.54 \\ 9 & 3328.5120 & 25.192 & \mathrm{G} & 10673175 & 0.27 \\ 10 & 3657.5668 & 27.417 & \mathrm{~A} & 5126136 & 0.38 \\ 11 & 4282.6486 & 30.874 & \mathrm{U}+\mathrm{Cm} & 15880661 & 0.21 \\ 12 & 4970.7665 & 34.609 & \mathrm{~A}+\mathrm{Gm} & 10873309 & 0.64 \\ 13 & 5299.8210 & 35.684 & \mathrm{~A} & 12807606 & 1.02 \\ 14 & 5511.8306 & 35.900 & \mathrm{Y} & 13088146 & 1.16 \\ 15 & 5840.8850 & 37.167 & \mathrm{~A} & 3623732 & 3.32 \\ 16 & 6146.9096 & 37.460 & \mathrm{U} & 1897334 & 3.04 \\ 17 & 6465.9704 & 38.006 & \mathrm{mC} & 2463925 & 1.78 \\ 18 & 6771.9928 & 38.393 & \mathrm{U} & 3706693 & 1.26 \\ 19 & 7117.0453 & 38.873 & \mathrm{G} & 3506106 & 3.47 \\ 20 & 7462.0964 & 39.527 & \mathrm{G} & 2455794 & 3.81 \\ 21 & 7791.1787 & 40.196 & \mathrm{~A} & 1226259 & 7.47 \\ 22 & 8136.1916 & 40.385 & \mathrm{G} & 1925167 & 2.91\end{array}$

Ts 13 Output Sequence:

5'-AGAGC2mGCCAGACmUGmAAY'AUmCUGGAG-3' 
Table S14. 5'_tRNA_T1_nonCMC_SII_042519s04_44g45a. Sequencing of 5'-non-CMCconverted tRNA segment II from $21 \mathrm{~A}$ to $45 \mathrm{~A}$ by the global hierarchical ranking algorithm. The output sequence is indicated at the bottom.

$\begin{array}{rrrlrr}\text { Fragment } & \text { Mass } & \text { RT } & \text { Base } & \text { Volume } & \text { PPM } \\ 1 & 692.1076 & 1.032 & \text { A+G } & 121835 & 4.19 \\ 2 & 1021.1576 & 1.264 & \mathrm{~A} & 548483 & 5.29 \\ 3 & 1366.2072 & 4.020 & \mathrm{G} & 2219430 & 2.34 \\ 4 & 1671.2480 & 7.304 & \mathrm{C} & 3142702 & 2.21 \\ 5 & 2044.3269 & 16.800 & 2 \mathrm{mG} & 1700693 & 1.71 \\ 6 & 2349.3689 & 18.430 & \mathrm{C} & 2431764 & 1.19 \\ 7 & 2654.4105 & 20.727 & \mathrm{C} & 6691067 & 0.94 \\ 8 & 2983.4639 & 23.756 & \mathrm{~A} & 9276684 & 0.54 \\ 9 & 3328.5120 & 25.192 & \mathrm{G} & 10673175 & 0.27 \\ 10 & 3657.5668 & 27.417 & \mathrm{~A} & 5126136 & 0.38 \\ 11 & 4282.6486 & 30.874 & \mathrm{U}+\mathrm{Cm} & 15880661 & 0.21 \\ 12 & 4970.7665 & 34.609 & \mathrm{~A}+\mathrm{Gm} & 10873309 & 0.64 \\ 13 & 5299.8210 & 35.684 & \mathrm{~A} & 12807606 & 1.02 \\ 14 & 5511.8306 & 35.900 & \mathrm{Y} & 13088146 & 1.16 \\ 15 & 5840.8850 & 37.167 & \mathrm{~A} & 3623732 & 3.32 \\ 16 & 6146.9096 & 37.460 & \mathrm{U} & 1897334 & 3.04 \\ 17 & 6465.9704 & 38.006 & \mathrm{mC} & 2463925 & 1.78 \\ 18 & 6771.9928 & 38.393 & \mathrm{U} & 3706693 & 1.26 \\ 19 & 7117.0453 & 38.873 & \mathrm{G} & 3506106 & 3.47 \\ 20 & 7462.0964 & 39.527 & \mathrm{G} & 2455794 & 3.81 \\ 21 & 7807.1385 & 39.523 & \mathrm{G} & 835117 & 1.52 \\ 22 & 8136.1916 & 40.385 & \mathrm{~A} & 1925167 & 1.54\end{array}$

Ts 14 Output Sequence:

5'-AGAGC2mGCCAGACmUGmAAY'AUmCUGGGA-3' 
Table S15. 5' tRNA_T1_CMC_SII_042519s04. Sequencing of 5'-CMC-converted tRNA segment II from $39 \psi$ to $44 \mathrm{~A}$ by the global hierarchical ranking algorithm. The output sequence is indicated at the bottom.

$\begin{array}{rrrlrr}\text { Fragment } & \text { Mass } & \text { RT } & \text { Base } & \text { Volume } & \text { PPM } \\ 1 & 6398.1211 & 44.707 & \text { Mod-Psi } & 1295323 & 2.97 \\ 2 & 6717.1789 & 45.223 & \mathrm{mC} & 2506731 & 2.96 \\ 3 & 7023.1878 & 45.283 & \mathrm{U} & 3037253 & 0.50 \\ 4 & 7368.2361 & 45.446 & \mathrm{G} & 8115206 & 0.58 \\ 5 & 7713.3006 & 45.574 & \mathrm{G} & 4221938 & 2.77 \\ 6 & 8042.3492 & 46.255 & \mathrm{~A} & 3190026 & 2.18\end{array}$

Ts 15 Output Sequence:

5'-4mCUGGA-3'

Mod-Psi is a symbol used in the global hierarchical ranking algorithm to designate pseudouridine $(\psi)$.

Table S16. 3' tRNA_T1_nonCMC_SII_042519s04. Sequencing of 3'-non-CMC-converted tRNA segment II from $5 \overline{7 \mathrm{G}}$ to $47 \mathrm{U}$ by the global hierarchical ranking algorithm. The output sequence is indicated at the bottom.

$\begin{array}{rrrlrr}\text { Fragment } & \text { Mass } & \mathrm{RT} & \text { Base } & \text { Volume } & \text { PPM } \\ 1 & 668.0943 & 0.968 & \mathrm{G}+\mathrm{C} & 79549 & 7.33 \\ 2 & 974.1302 & 0.915 & \mathrm{U} & 826458 & 5.85 \\ 3 & 1294.1594 & 2.732 & \mathrm{~T} & 403523 & 4.71 \\ 4 & 1639.2089 & 6.500 & \mathrm{G} & 789168 & 2.44 \\ 5 & 1945.2357 & 6.129 & \mathrm{U} & 190380 & 1.29 \\ 6 & 2290.2818 & 10.466 & \mathrm{G} & 1584520 & 1.66 \\ 7 & 2596.3069 & 12.965 & \mathrm{U} & 1100858 & 1.54 \\ 8 & 2915.3646 & 17.907 & \mathrm{mC} & 1557574 & 1.10 \\ 9 & 3220.4052 & 18.523 & \mathrm{C} & 773618 & 1.21 \\ 10 & 3526.4333 & 20.318 & \mathrm{U} & 2252901 & 0.31\end{array}$

Ts 16 Output Sequence:

5'-UCmCUGUGTUCG-3' 
Table S17. 3'_tRNA_T1_CMC_SII_042519s04. Sequencing of 3'-CMC converted tRNA segment II from $57 \mathrm{G}$ to $47 \mathrm{U}$ by the global hierarchical ranking algorithm. The output sequence is indicated at the bottom.

$\begin{array}{rrrlrr}\text { Fragment } & \text { Mass } & \text { RT } & \text { Base } & \text { Volume } & \text { PPM } \\ 1 & 1225.3215 & 14.484 & \text { Mod-Psi } & 882395 & 2.29 \\ 2 & 1545.3611 & 19.764 & \text { T } & 78086 & 2.72 \\ 3 & 1890.4097 & 27.200 & \text { G } & 1324986 & 1.59 \\ 4 & 2196.4340 & 25.561 & \text { U } & 33874 & 1.82 \\ 5 & 2541.4824 & 27.899 & \text { G } & 3029272 & 1.18 \\ 6 & 2847.5087 & 28.729 & \text { U } & 2275337 & 0.70 \\ 7 & 3166.5661 & 32.358 & \mathrm{mC} & 2499558 & 0.47 \\ 8 & 3471.6055 & 32.073 & \mathrm{C} & 2485944 & 1.01 \\ 9 & 3777.6332 & 32.777 & \mathrm{U} & 4553148 & 0.29\end{array}$

Ts 17 Output Sequence:

5'-UCmCUGUGT $\psi-3^{\prime}$

Table S18. Detection of $Y^{\prime}$ in the presence of tRNA before (in full-length tRNA) and after (as an isolated base) acid degradation.

\begin{tabular}{|c|c|c|c|c|c|c|c|}
\hline In a form of segment II & $\begin{array}{c}\text { Calc mass } \\
\text { (Da) }\end{array}$ & $\begin{array}{c}\text { Exp mass } \\
\text { (Da) }\end{array}$ & $\mathbf{m} / \mathbf{z}$ & EIC ratio & Percent & QS & ppm \\
\hline Y before acid degradation & 12361.805 & 12361.841 & 823.1141 & 0.90 & $90 \%$ & 80 & -2.9 \\
\hline $\mathrm{Y}^{\prime}$ before acid degradation & 12003.666 & 12003.762 & 922.359 & 0.10 & $10 \%$ & 48 & -7.9 \\
\hline $\mathrm{Y}^{\prime}$ after acid degradation & 376.1495 & 376.1479 & 375.1409 & 1.0 & $100 \%$ & 100 & 4.3 \\
\hline
\end{tabular}


Table S19. The relative percentages of 11 modifications at each position were quantified by integrating the EIC peaks of their corresponding ladder fragments from tRNA.

\begin{tabular}{|c|c|c|c|c|c|c|c|}
\hline Position & Modification & Fragment & Formula & Mass (Da) & $\mathbf{m} / \mathbf{z}$ & EIC ratio & Percent \\
\hline \multirow{2}{*}{10} & $\mathrm{~m}^{2} \mathrm{G}$ & $1 \mathrm{G}-10$ & C97H122N39O75 & 3373.4045 & 673.6734 & 1.0 & $100 \%$ \\
\hline & $\mathrm{G}$ & $1 \mathrm{G}-10 \mathrm{G}$ & C96H120N39O75 & 3359.3889 & - & - & - \\
\hline \multirow{2}{*}{16} & $\mathrm{D}$ & $1 \mathrm{G}-16 \mathrm{D}$ & C153H194N59O11 & 5271.6533 & 657.9480 & 1.0 & $100 \%$ \\
\hline & $\mathrm{U}$ & $1 \mathrm{G}-16 \mathrm{U}$ & C153H192N59O11 & 5269.6376 & - & - & - \\
\hline \multirow{2}{*}{17} & $\mathrm{D}$ & $1 \mathrm{G}-17 \mathrm{D}$ & $\mathrm{C} 162 \mathrm{H} 207 \mathrm{~N} 61 \mathrm{O} 12$ & 5579.6942 & 696.4556 & 1.0 & $100 \%$ \\
\hline & $\mathrm{U}$ & $1 \mathrm{G}-17 \mathrm{U}$ & C162H205N61O12 & 5577.6786 & - & - & - \\
\hline \multirow{3}{*}{26} & $\mathrm{~m}_{2}^{2} \mathrm{G}$ & $21 \mathrm{~A}-26$ & C61H78N28O41P & 2044.3305 & 680.4350 & 0.58 & $58 \%$ \\
\hline & $\mathrm{mG}$ & $21 \mathrm{~A}-26$ & C60H76N28O41P & 2030.3148 & - & - & - \\
\hline & G & $21 \mathrm{~A}-26 \mathrm{G}$ & C59H74N28O41P & 2016.2992 & 503.0664 & 0.42 & $42 \%$ \\
\hline \multirow{2}{*}{32} & $\mathrm{Cm}$ & $21 \mathrm{~A}-32$ & C128H163N54O89 & 4282.6478 & 610.7992 & 1.0 & $100 \%$ \\
\hline & $\mathrm{C}$ & $21 \mathrm{~A}-32 \mathrm{C}$ & C118H150N52O81 & 3962.6068 & - & - & - \\
\hline \multirow{2}{*}{34} & $\mathrm{Gm}$ & $21 \mathrm{~A}-34$ & C149H189N64O10 & 4970.7634 & 709.1020 & 0.60 & $60 \%$ \\
\hline & G & $21 \mathrm{~A}-34 \mathrm{G}$ & C138H175N59O96 & 4627.6952 & 660.0906 & 0.40 & $40 \%$ \\
\hline \multirow{2}{*}{37} & $\mathrm{Y}$ & $21 \mathrm{~A}-57 \mathrm{G}$ & C373H469N146O2 & 12361.805 & 823.1141 & 0.90 & $90 \%$ \\
\hline & $\mathrm{Y}^{\prime}$ & $21 \mathrm{~A}-57 \mathrm{G}$ & $\mathrm{C} 357 \mathrm{H} 451 \mathrm{~N} 140 \mathrm{O} 2$ & 12003.666 & 922.359 & 0.10 & $10 \%$ \\
\hline \multirow{3}{*}{39} & CMC-converted $\psi$ & $21 \mathrm{~A}-44 \mathrm{~A}$ & C246H319N99O16 & 8042.3318 & 803.2263 & 0.79 & $79 \%$ \\
\hline & Non-converted $\psi$ & $21 \mathrm{~A}-44 \mathrm{~A}$ & C232H294N96O16 & 7791.1320 & 778.1111 & 0.21 & $21 \%$ \\
\hline & Calibrated $\Psi$ & $21 \mathrm{~A}-44 \mathrm{~A}$ & C232H294N96O16 & 7791.1320 & - & - & $100 \% *$ \\
\hline \multirow{2}{*}{40} & $\mathrm{~m}^{5} \mathrm{C}$ & $21 \mathrm{~A}-40$ & $\mathrm{C} 193 \mathrm{H} 247 \mathrm{~N} 79 \mathrm{O} 13$ & 6465.9592 & 717.4318 & 1.0 & $100 \%$ \\
\hline & $\mathrm{C}$ & $21 \mathrm{~A}-40 \mathrm{C}$ & C192H245N79O13 & 6451.9436 & - & - & - \\
\hline \multirow{2}{*}{46} & $\mathrm{~m}^{7} \mathrm{G}$ & $21 \mathrm{~A}-46$ & $\mathrm{C} 253 \mathrm{H} 320 \mathrm{~N} 106 \mathrm{O} 1$ & 8495.2425 & 771.2866 & 0.46 & $46 \%$ \\
\hline & G & $21 \mathrm{~A}-46 \mathrm{G}$ & $\mathrm{C} 252 \mathrm{H} 318 \mathrm{~N} 106 \mathrm{O} 1$ & 8481.2268 & 770.0160 & 0.54 & $54 \%$ \\
\hline \multirow{2}{*}{49} & $\mathrm{~m}^{5} \mathrm{C}$ & $21 \mathrm{~A}-49$ & $\mathrm{C} 281 \mathrm{H} 357 \mathrm{~N} 114 \mathrm{O} 2$ & 9425.3660 & 784.5296 & 1.0 & $100 \%$ \\
\hline & $\mathrm{C}$ & $21 \mathrm{~A}-49 \mathrm{C}$ & $\mathrm{C} 280 \mathrm{H} 355 \mathrm{~N} 114 \mathrm{O} 2$ & 9411.3503 & - & - & - \\
\hline \multirow{2}{*}{54} & $\mathrm{~T}$ & $21 \mathrm{~A}-54 \mathrm{~T}$ & $\mathrm{C} 329 \mathrm{H} 416 \mathrm{~N} 130 \mathrm{O} 2$ & 11047.552 & 848.8105 & 1.0 & $100 \%$ \\
\hline & $\mathrm{U}$ & $21 \mathrm{~A}-54 \mathrm{U}$ & C328H414N130O2 & 11033.536 & - & - & - \\
\hline \multirow{3}{*}{55} & CMC-converted $\psi$ & $47 \mathrm{U}-57 \mathrm{G}$ & C118H158N37O84 & 3777.6342 & 628.5979 & 0.76 & $76 \%$ \\
\hline & Non-converted & $47 \mathrm{U}-57 \mathrm{G}$ & C104H133N34O83 & 3526.4344 & 586.7314 & 0.24 & $24 \%$ \\
\hline & Calibrated $\Psi$ & $47 \mathrm{U}-57 \mathrm{G}$ & C104H133N34O83 & 3526.4344 & - & - & $100 \% *$ \\
\hline \multirow{2}{*}{58} & $\mathrm{~m}^{1} \mathrm{~A}$ & $58 \mathrm{~m}^{1} \mathrm{~A}-75$ & C203H270N73O13 & 6558.1089 & 727.6724 & 0.94 & $94 \%$ \\
\hline & $\mathrm{A}$ & $58 \mathrm{~A}-75 \mathrm{C}$ & $\mathrm{C} 202 \mathrm{H} 268 \mathrm{~N} 73 \mathrm{O} 13$ & 6544.0933 & 722.7936 & 0.06 & $6 \%$ \\
\hline
\end{tabular}

*Please note: Integration of the EIC peak of CMC- $\Psi$-containing ladder fragment was used for the percentage quantification, but when we factored in the yield of the conversion of the $\Psi$ to the CMC- $\Psi$ $(\sim 70 \%)$, this position would be $\sim 100 \%$ of $\Psi$. Parts highlighted in pink are related to partially modified nucleotides. 
Table S20. 3'_OH_tRNA_T1_SII_111418s05_44A45G. LC-MS analysis of segment II from $34 \mathrm{Gm}$ to $55 \psi$. Below are all sequence ladder components when reading from $3{ }^{\prime}$ - to 5 '-direction. The sequence was manually verified and is displayed at the bottom.

\begin{tabular}{|c|c|c|c|c|c|c|c|c|}
\hline \multicolumn{4}{|c}{ Theoretical } & \multicolumn{3}{c|}{ Extracted data file after LC/MS analysis } & Error \\
\hline Fragments & Theoretical mass & $\begin{array}{c}\text { Base } \\
\text { mass }\end{array}$ & Base & MFE mass & $\mathbf{t}_{\mathbf{R}}$ & Volume & Quality Score & ppm \\
\hline 21 & 7739.0291 & 688.1156 & $\mathrm{~A}+\mathrm{Gm}$ & 7739.0198 & 28.919 & 572629 & 80 & 1.20 \\
\hline 20 & 7050.9135 & 329.0525 & $\mathrm{~A}$ & 7050.9277 & 26.539 & 413840 & 60 & -2.01 \\
\hline 19 & 6721.8610 & 212.0086 & $\mathrm{Y}^{\prime}$ & 6721.8635 & 24.741 & 381223 & 72.8 & -0.37 \\
\hline 18 & 6509.8524 & 329.0525 & $\mathrm{~A}$ & 6509.8604 & 25.336 & 1019699 & 80 & -1.23 \\
\hline 17 & 6180.7999 & 306.0253 & $\psi$ & 6180.8037 & 23.079 & 707995 & 77.8 & -0.61 \\
\hline 16 & 5874.7746 & 319.0570 & $\mathrm{~m}^{5} \mathrm{C}$ & 5874.7783 & 23.641 & 2167527 & 100 & -0.63 \\
\hline 15 & 5555.7176 & 306.0253 & $\mathrm{U}$ & 5555.7209 & 21.539 & 1146864 & 98.5 & -0.59 \\
\hline 14 & 5249.6923 & 345.0474 & $\mathrm{G}$ & 5249.6958 & 20.605 & 1609784 & 100 & -0.67 \\
\hline 13 & 4904.6449 & 345.0475 & $\mathrm{G}$ & 4904.6446 & 19.764 & 1791176 & 100 & 0.06 \\
\hline 12 & 4559.5974 & 329.0525 & $\mathrm{~A}$ & 4559.5918 & 19.341 & 974223 & 80 & 1.23 \\
\hline 11 & 4230.5449 & 345.0474 & $\mathrm{G}$ & 4230.5449 & 16.828 & 1254040 & 99.7 & 0.00 \\
\hline 10 & 3885.4975 & 359.0631 & $\mathrm{~m}^{7} \mathrm{G}$ & 3885.4957 & 15.319 & 1940572 & 95.7 & 0.46 \\
\hline 9 & 3526.4344 & 306.0253 & $\mathrm{U}$ & 3526.4327 & 13.475 & 1011995 & 100 & 0.48 \\
\hline 8 & 3220.4091 & 305.0413 & $\mathrm{C}$ & 3220.4066 & 11.393 & 2082145 & 100 & 0.78 \\
\hline 7 & 2915.3678 & 319.0569 & $\mathrm{~m}^{5} \mathrm{C}$ & 2915.3648 & 10.586 & 3108932 & 100 & 1.03 \\
\hline 6 & 2596.3109 & 306.0253 & $\mathrm{U}$ & 2596.3066 & 6.488 & 523377 & 42.8 & 1.66 \\
\hline 5 & 2290.2856 & 345.0475 & $\mathrm{G}$ & 2290.2828 & 3.961 & 2464626 & 94.7 & 1.22 \\
\hline 4 & 1945.2381 & 306.0253 & $\mathrm{U}$ & 1945.2379 & 1.074 & 637786 & 83.4 & 0.10 \\
\hline 3 & 1639.2128 & 345.0474 & $\mathrm{G}$ & 1639.2106 & 1.034 & 2301078 & 100 & 1.34 \\
\hline 2 & 1294.1654 & 320.0409 & $\mathrm{~T}$ & 1294.1737 & 8.127 & 78112 & 67.5 & -6.41 \\
\hline 1 & 974.1245 & 306.0253 & $\psi$ & 974.1240 & 0.936 & 143886 & 79.1 & 0.51 \\
\hline
\end{tabular}

Ts 20 Output Sequence:

5'-GmAAY'A $\psi$ mCUGGAGmGUCmCUGUGT $\psi$-3' 
Table S21. 3'_OH_tRNA_T1_SII_111418s05_44g45a. LC-MS analysis of segment II from $34 \mathrm{Gm}$ to $55 \psi$. Below are all sequence ladder components when reading from 3 ' - to $5^{\prime}$-direction. The sequence was manually verified and is displayed at the bottom.

\begin{tabular}{|c|c|c|c|c|c|c|c|c|}
\hline \multicolumn{4}{|c}{ Theoretical } & \multicolumn{3}{c|}{ Extracted data file after LC/MS analysis } & Error \\
\hline Fragments & Theoretical mass & $\begin{array}{c}\text { Base } \\
\text { mass }\end{array}$ & Base & MFE mass & $\mathbf{t}_{\mathbf{R}}$ & Volume & Quality Score & ppm \\
\hline 21 & 7739.0291 & 688.1156 & $\mathrm{~A}+\mathrm{Gm}$ & 7739.0198 & 28.919 & 572629 & 80 & 1.20 \\
\hline 20 & 7050.9135 & 329.0525 & $\mathrm{~A}$ & 7050.9277 & 26.539 & 413840 & 60 & -2.01 \\
\hline 19 & 6721.8610 & 212.0086 & $\mathrm{Y}^{\prime}$ & 6721.8635 & 24.741 & 381223 & 72.8 & -0.37 \\
\hline 18 & 6509.8524 & 329.0525 & $\mathrm{~A}$ & 6509.8604 & 25.336 & 1019699 & 80 & -1.23 \\
\hline 17 & 6180.7999 & 306.0253 & $\psi$ & 6180.8037 & 23.079 & 707995 & 77.8 & -0.61 \\
\hline 16 & 5874.7746 & 319.0570 & $\mathrm{~m}^{5} \mathrm{C}$ & 5874.7783 & 23.641 & 2167527 & 100 & -0.63 \\
\hline 15 & 5555.7176 & 306.0253 & $\mathrm{U}$ & 5555.7209 & 21.539 & 1146864 & 98.5 & -0.59 \\
\hline 14 & 5249.6923 & 345.0474 & $\mathrm{G}$ & 5249.6958 & 20.605 & 1609784 & 100 & -0.67 \\
\hline 13 & 4904.6449 & 345.0475 & $\mathrm{G}$ & 4904.6446 & 19.764 & 1791176 & 100 & 0.06 \\
\hline 12 & 4559.5974 & 345.0474 & $\mathrm{G}$ & 4559.5918 & 19.341 & 974223 & 80 & -2.94 \\
\hline 11 & 4214.5500 & 329.0525 & $\mathrm{~A}$ & 4214.5624 & 18.424 & 273170 & 79.6 & 0.46 \\
\hline 10 & 3885.4975 & 359.0631 & $\mathrm{~m}^{7} \mathrm{G}$ & 3885.4957 & 15.319 & 1940572 & 95.7 & 0.46 \\
\hline 9 & 3526.4344 & 306.0253 & $\mathrm{U}$ & 3526.4327 & 13.475 & 1011995 & 100 & 0.48 \\
\hline 8 & 3220.4091 & 305.0413 & $\mathrm{C}$ & 3220.4066 & 11.393 & 2082145 & 100 & 0.78 \\
\hline 7 & 2915.3678 & 319.0569 & $\mathrm{~m}^{5} \mathrm{C}$ & 2915.3648 & 10.586 & 3108932 & 100 & 1.03 \\
\hline 6 & 2596.3109 & 306.0253 & $\mathrm{U}$ & 2596.3066 & 6.488 & 523377 & 42.8 & 1.66 \\
\hline 5 & 2290.2856 & 345.0475 & $\mathrm{G}$ & 2290.2828 & 3.961 & 2464626 & 94.7 & 1.22 \\
\hline 4 & 1945.2381 & 306.0253 & $\mathrm{U}$ & 1945.2379 & 1.074 & 637786 & 83.4 & 0.10 \\
\hline 3 & 1639.2128 & 345.0474 & $\mathrm{G}$ & 1639.2106 & 1.034 & 2301078 & 100 & 1.34 \\
\hline 2 & 1294.1654 & 320.0409 & $\mathrm{~T}$ & 1294.1737 & 8.127 & 78112 & 67.5 & -6.41 \\
\hline 1 & 974.1245 & 306.0253 & $\psi$ & 974.1240 & 0.936 & 143886 & 79.1 & 0.51 \\
\hline
\end{tabular}

Ts 21 Output Sequence:

5'-GmAAY'A $\psi$ mCUGGGAmGUCmCUGUGT $\psi-3$ ' 
Table S22. 3'_OH_tRNA_T1_SII_032919s07_44A45G. LC-MS analysis of segment II from 30G to $55 \psi$. Below are all sequence ladder components when reading from $3^{\prime}-$ to $5^{\prime}$-direction. The sequence was manually verified and is displayed at the bottom.

\begin{tabular}{|c|c|c|c|c|c|c|c|c|}
\hline \multicolumn{4}{|c|}{ Theoretical } & \multicolumn{4}{|c|}{ Extracted data file after LC/MS analysis } & \multirow{2}{*}{$\begin{array}{c}\text { Error } \\
\text { ppm }\end{array}$} \\
\hline Fragments & Theoretical mass & $\begin{array}{l}\text { Base } \\
\text { mass }\end{array}$ & Base & MFE mass & $\mathbf{t}_{\mathbf{R}}$ & Volume & Quality Score & \\
\hline 24 & 9038.2113 & 345.0474 & $\mathrm{G}$ & 9038.133 & 37.926 & 394860 & 60.8 & 8.66 \\
\hline 23 & 8693.1639 & 329.0525 & A & 8693.1871 & 38.113 & 174673 & 41.4 & -2.67 \\
\hline 22 & 8364.1114 & 625.0823 & $\mathrm{U}+\mathrm{Cm}$ & 8364.1502 & 37.005 & 133633 & 41.9 & -4.64 \\
\hline 21 & 7739.0291 & 688.1156 & $\mathrm{~A}+\mathrm{Gm}$ & 7739.0557 & 35.391 & 650792 & 77.4 & -3.44 \\
\hline 20 & 7050.9135 & 329.0525 & A & 7050.9339 & 32.627 & 590137 & 78.5 & -2.89 \\
\hline 19 & 6721.8610 & 212.0086 & $\mathrm{Y}^{\prime}$ & 6721.8845 & 30.813 & 764391 & 80 & -3.50 \\
\hline 18 & 6509.8524 & 329.0525 & A & 6509.864 & 31.762 & 1166876 & 80 & -1.78 \\
\hline 17 & 6180.7999 & 306.0253 & $\psi$ & 6180.7968 & 29.159 & 148437 & 65.9 & 0.50 \\
\hline 16 & 5874.7746 & 319.0570 & $\mathrm{~m}^{5} \mathrm{C}$ & 5874.7784 & 30.31 & 1368105 & 79.9 & -0.65 \\
\hline 15 & 5555.7176 & 306.0253 & $\mathrm{U}$ & 5555.7219 & 27.737 & 1148576 & 80 & -0.77 \\
\hline 14 & 5249.6923 & 345.0474 & G & 5249.7098 & 26.957 & 1297236 & 80 & -3.33 \\
\hline 13 & 4904.6449 & 345.0475 & $\mathrm{G}$ & 4904.6497 & 26.195 & 1021939 & 90 & -0.98 \\
\hline 12 & 4559.5974 & 329.0525 & A & 4559.5974 & 25.942 & 1209559 & 99 & 0.00 \\
\hline 11 & 4230.5449 & 345.0474 & G & 4230.5461 & 23.338 & 927818 & 92.3 & -0.28 \\
\hline 10 & 3885.4975 & 359.0631 & $\mathrm{~m}^{7} \mathrm{G}$ & 3885.4975 & 21.811 & 1357508 & 90.5 & 0.00 \\
\hline 9 & 3526.4344 & 306.0253 & $\mathrm{U}$ & 3526.4332 & 20.034 & 1078413 & 98.3 & 0.34 \\
\hline 8 & 3220.4091 & 305.0413 & $\mathrm{C}$ & 3220.4063 & 18.209 & 1434999 & 100 & 0.87 \\
\hline 7 & 2915.3678 & 319.0569 & $\mathrm{~m}^{5} \mathrm{C}$ & 2915.366 & 17.589 & 2388681 & 100 & 0.62 \\
\hline 6 & 2596.3109 & 306.0253 & $\mathrm{U}$ & 2596.308 & 12.655 & 1592241 & 100 & 1.12 \\
\hline 5 & 2290.2856 & 345.0475 & G & 2290.2828 & 10.189 & 2053112 & 100 & 1.22 \\
\hline 4 & 1945.2381 & 306.0253 & $\mathrm{U}$ & 1945.2371 & 6.47 & 1359480 & 77.8 & 0.51 \\
\hline 3 & 1639.2128 & 345.0474 & $\mathrm{G}$ & 1639.21 & 4.723 & 1598482 & 100 & 1.71 \\
\hline 2 & 1294.1654 & 320.0409 & $\mathrm{~T}$ & 1294.1615 & 2.282 & 620026 & 100 & 3.01 \\
\hline 1 & 974.1245 & 306.0253 & $\psi$ & 974.1225 & 0.875 & 221837 & 90.6 & 2.05 \\
\hline
\end{tabular}

Ts 22 Output Sequence:

5'-GACmUGmAAY'AUmCUGGAGmGUCmCUGUGTU-3' 
Table S23. 3'_OH_tRNA_T1_SII_032919s07_44g45a. LC-MS analysis of segment II from 30G to $55 \psi$. Below are all sequence ladder components when reading from $3^{\prime}-$ to $5^{\prime}$-direction. The sequence was manually verified and is displayed at the bottom.

\begin{tabular}{|c|c|c|c|c|c|c|c|c|}
\hline \multicolumn{4}{|c|}{ Theoretical } & \multicolumn{4}{|c|}{ Extracted data file after LC/MS analysis } & \multirow{2}{*}{$\begin{array}{c}\text { Error } \\
\text { ppm }\end{array}$} \\
\hline Fragments & Theoretical mass & $\begin{array}{l}\text { Base } \\
\text { mass }\end{array}$ & Base & MFE mass & $\mathbf{t}_{\mathbf{R}}$ & Volume & Quality Score & \\
\hline 24 & 9038.2113 & 345.0474 & $\mathrm{G}$ & 9038.133 & 37.926 & 394860 & 60.8 & 8.66 \\
\hline 23 & 8693.1639 & 329.0525 & A & 8693.1871 & 38.113 & 174673 & 41.4 & -2.67 \\
\hline 22 & 8364.1114 & 625.0823 & $\mathrm{U}+\mathrm{Cm}$ & 8364.1502 & 37.005 & 133633 & 41.9 & -4.64 \\
\hline 21 & 7739.0291 & 688.1156 & $\mathrm{~A}+\mathrm{Gm}$ & 7739.0557 & 35.391 & 650792 & 77.4 & -3.44 \\
\hline 20 & 7050.9135 & 329.0525 & A & 7050.9339 & 32.627 & 590137 & 78.5 & -2.89 \\
\hline 19 & 6721.8610 & 212.0086 & $\mathrm{Y}^{\prime}$ & 6721.8845 & 30.813 & 764391 & 80 & -3.50 \\
\hline 18 & 6509.8524 & 329.0525 & A & 6509.864 & 31.762 & 1166876 & 80 & -1.78 \\
\hline 17 & 6180.7999 & 306.0253 & $\psi$ & 6180.7968 & 29.159 & 148437 & 65.9 & 0.50 \\
\hline 16 & 5874.7746 & 319.0570 & $\mathrm{~m}^{5} \mathrm{C}$ & 5874.7784 & 30.31 & 1368105 & 79.9 & -0.65 \\
\hline 15 & 5555.7176 & 306.0253 & $\mathrm{U}$ & 5555.7219 & 27.737 & 1148576 & 80 & -0.77 \\
\hline 14 & 5249.6923 & 345.0474 & G & 5249.7098 & 26.957 & 1297236 & 80 & -3.33 \\
\hline 13 & 4904.6449 & 345.0475 & $\mathrm{G}$ & 4904.6497 & 26.195 & 1021939 & 90 & -0.98 \\
\hline 12 & 4559.5974 & 345.0474 & $\mathrm{G}$ & 4559.5974 & 25.942 & 1209559 & 99 & 0.00 \\
\hline 11 & 4214.5500 & 329.0525 & A & 4214.5534 & 24.918 & 299777 & 60 & -0.81 \\
\hline 10 & 3885.4975 & 359.0631 & $\mathrm{~m}^{7} \mathrm{G}$ & 3885.4975 & 21.811 & 1357508 & 90.5 & 0.00 \\
\hline 9 & 3526.4344 & 306.0253 & $\mathrm{U}$ & 3526.4332 & 20.034 & 1078413 & 98.3 & 0.34 \\
\hline 8 & 3220.4091 & 305.0413 & $\mathrm{C}$ & 3220.4063 & 18.209 & 1434999 & 100 & 0.87 \\
\hline 7 & 2915.3678 & 319.0569 & $\mathrm{~m}^{5} \mathrm{C}$ & 2915.366 & 17.589 & 2388681 & 100 & 0.62 \\
\hline 6 & 2596.3109 & 306.0253 & $\mathrm{U}$ & 2596.308 & 12.655 & 1592241 & 100 & 1.12 \\
\hline 5 & 2290.2856 & 345.0475 & G & 2290.2828 & 10.189 & 2053112 & 100 & 1.22 \\
\hline 4 & 1945.2381 & 306.0253 & $\mathrm{U}$ & 1945.2371 & 6.47 & 1359480 & 77.8 & 0.51 \\
\hline 3 & 1639.2128 & 345.0474 & $\mathrm{G}$ & 1639.21 & 4.723 & 1598482 & 100 & 1.71 \\
\hline 2 & 1294.1654 & 320.0409 & $\mathrm{~T}$ & 1294.1615 & 2.282 & 620026 & 100 & 3.01 \\
\hline 1 & 974.1245 & 306.0253 & $\psi$ & 974.1225 & 0.875 & 221837 & 90.6 & 2.05 \\
\hline
\end{tabular}

Ts 23 Output Sequence:

5'-GACmUGmAAY'AUmCUGGGAmGUCmCUGUGTU-3' 
Table S24. Quantification of the relative population of the three isoforms of tRNA based on integration of EIC of RNase T1 digested products of tRNA. ${ }^{8}$

\begin{tabular}{|c|c|c|c|c|c|c|c|}
\hline Fragment & Calc mass (Da) & Exp mass (Da) & $\mathbf{m} / \mathbf{z}$ & EIC ratio & Percent & QS & ppm \\
\hline $58 \mathrm{~m}^{1} \mathrm{~A}$ to $74 \mathrm{C}$ & 5364.7935 & 5364.7939 & 595.0800 & 0.03 & $3 \%$ & 98 & -0.1 \\
\hline $58 \mathrm{~m}^{1} \mathrm{~A}$ to $75 \mathrm{C}$ & 5669.8348 & 5669.8403 & 628.9753 & 0.80 & $80 \%$ & 100 & -1.0 \\
\hline $58 \mathrm{~m}^{1} \mathrm{~A}$ to $76 \mathrm{~A}$ & 5998.8873 & 5998.8845 & 598.8828 & 0.17 & $17 \%$ & 100 & 0.5 \\
\hline
\end{tabular}

Table S25. Detection of wild type (44A45G) and transition/edited form (44g45a) tRNA, respectively, in three datasets by the global hierarchical ranking algorithm (refer to output files in Tables S4, S5, S8, S9, S13, and S14).

\begin{tabular}{|c|c|c|c|c|c|c|c|c|}
\hline \multirow[b]{2}{*}{ Dataset } & \multicolumn{2}{|c|}{ Wild type (I) } & \multicolumn{2}{|c|}{ Transition form (II) } & \multirow{2}{*}{$\begin{array}{c}\text { I } \\
\%\end{array}$} & \multirow{2}{*}{$\begin{array}{c}\text { I } \\
\text { Mean } \pm \\
\text { SEM }\end{array}$} & \multirow{2}{*}{$\begin{array}{l}\text { II } \\
\%\end{array}$} & \multirow{2}{*}{$\begin{array}{c}\text { II } \\
\text { Mean } \pm \\
\text { SEM }\end{array}$} \\
\hline & $\mathbf{m} / \mathbf{z}$ & $\begin{array}{c}\text { EIC ratio } \\
(44 \mathrm{~A})\end{array}$ & $\mathbf{m} / \mathbf{z}$ & $\begin{array}{c}\text { EIC ratio } \\
(44 \mathrm{~g})\end{array}$ & & & & \\
\hline Labeled segment II & 836.1243 & 0.54 & 837.6269 & 0.46 & 54 & \multirow{3}{*}{$50.4 \pm 3.2 \%$} & 46 & \multirow{3}{*}{$49.6 \pm 3.2 \%$} \\
\hline Unlabeled segment II & 778.4074 & 0.44 & 780.0080 & 0.56 & 44 & & 56 & \\
\hline Non-CMC-converted segment II & 778.4077 & 0.53 & 779.7066 & 0.47 & 53 & & 47 & \\
\hline
\end{tabular}

*Form I: 44A45G; Form II: 44g45a

Form I \% = EIC (44A) / [EIC (44A) + EIC (44g)]; Form II \% = EIC (44g) / [EIC (44A) + EIC (44g)] 


\section{References:}

[1] Zhang, N., Shi, S., Jia, T. Z., Ziegler, A., Yoo, B., Yuan, X., Li, W., and Zhang, S. (2019) A general LC-MS-based RNA sequencing method for direct analysis of multiple-base modifications in RNA mixtures, Nucleic Acids Res 47, e125.

[2] Bakin, A., and Ofengand, J. (1993) Four newly located pseudouridylate residues in Escherichia coli $23 \mathrm{~S}$ ribosomal RNA are all at the peptidyltransferase center: analysis by the application of a new sequencing technique, Biochemistry 32, 97549762.

[3] Wintermeyer, W., and Zachau, H. G. (1970) Specific Chemical Chain Scission of Transfer Rna at 7-Methylguanosine, Febs Letters 11, 160-164.

[4] Marchand, V., Ayadi, L., Ernst, F. G. M., Herder, J., Bourguignon-Igel, V., Galvanin, A., Kotter, A., Helm, M., Lafontaine, D. L. J., and Motorin, Y. (2018) AlkAnilineSeq: Profiling of $\mathrm{m}(7) \mathrm{G}$ and $\mathrm{m}(3) \mathrm{C}$ RNA Modifications at Single Nucleotide Resolution, Angew Chem Int Edit 57, 16785-16790.

[5] Ingle, S., Azad, R. N., Jain, S. S., and Tullius, T. D. (2014) Chemical probing of RNA with the hydroxyl radical at single-atom resolution, Nucleic Acids Res 42, 1275812767.

[6] Costa, M., and Monachello, D. (2014) Probing RNA folding by hydroxyl radical footprinting, Methods Mol Biol 1086, 119-142.

[7] Björkbom, A., Lelyveld, V. S., Zhang, S., Zhang, W., Tam, C. P., Blain, J. C., and Szostak, J. W. (2015) Bidirectional direct sequencing of noncanonical RNA by two-dimensional analysis of mass chromatograms, J Am Chem Soc 137, 1443014438.

[8] Zhang, S. L., Blain, J. C., Zielinska, D., Gryaznov, S. M., and Szostak, J. W. (2013) Fast and accurate nonenzymatic copying of an RNA-like synthetic genetic polymer, Proc Natl Acad Sci USA 110, 17732-17737.

[9] Motorin, Y., Muller, S., Behm-Ansmant, I., and Branlant, C. (2007) Identification of modified residues in RNAs by reverse transcription-based methods, Methods Enzymol 425, 21-53. 